\title{
RESEARCH
}

\section{How can social media analytics assist authorities in pandemic-related policy decisions? Insights from Australian states and territories}

Tan Yigitcanlar ${ }^{1 *} \mathbb{D}$, Nayomi Kankanamge ${ }^{1} \mathbb{D}$, Alexander Preston ${ }^{1}$, Palvinderjit Singh Gill ${ }^{1}$, Maqsood Rezayee ${ }^{2}$, Mahsan Ostadnia ${ }^{3}$, Bo Xia ${ }^{1}$ [D and Giuseppe loppolo ${ }^{4}$

\begin{abstract}
Background and objectives: Due to COVID-19, various countries introduced lockdowns and limited citizen movements. These restrictions triggered an increased use of digital technologies and platforms by the public. This provides an opportunity for the authorities to capture public perceptions on COVID-19 from social media channels to make informed decisions. The use of social media analytics during pandemics for decision-making, however, is an understudied area of research. Thus, this study aims to generate insights into how social media analytics can assist authorities in pandemic-related policy decisions.

Methods: This study involved a social media analysis approach - i.e., systematic geo-Twitter analysis - that contains descriptive, content, sentiment, and spatial analyses. Australian states and territories are selected as the case study context for the empirical investigation. This study collected 96,666 geotagged tweets (originated from Australia between 1 January and 4 May 2020), and analysed 35,969 of them after data cleaning.

Results: The findings disclose that: (a) Social media analytics is an efficient approach to capture the attitudes and perceptions of the public during a pandemic; (b) Crowdsourced social media data can guide interventions and decisions of the authorities during a pandemic, and; (c) Effective use of government social media channels can help the public to follow the introduced measures/restrictions.

Conclusion: The findings are invaluable for authorities to understand community perceptions and identify communities in needs and demands in a pandemic situation, where authorities are not in a position to conduct direct and lengthily public consultations.
\end{abstract}

Keywords: COVID-19, Pandemic-related policy, Social media analytics, Crowdsources data, Urban informatics, Australia

\section{Introduction}

Human-beings have witnessed many pandemic events with catastrophic impacts on the health and socioeconomic wellbeing $[1,2]$. Yellow fever outbreak, cholera, plague, tuberculosis, Spanish flu, Ebola, AIDS, influenza,

\footnotetext{
*Correspondence: tan.yigitcanlar@qut.edu.au

${ }^{1}$ School of Built Environment, Queensland University of Technology, 2 George Street, Brisbane, QLD 4000, Australia

Full list of author information is available at the end of the article
}

and West Nile disease are among some notable examples of pandemics [3].

Since the 80s, the globalisation process of the world has increased the threat of diseases as well as accelerated the spread of novel viruses [4]. The latest one, the novel coronavirus (SARS-CoV-2) has been spreading globally since its outbreak and rapid transmission in late 2019 in Wuhan, China. World Health Organization (WHO) termed the infection as COVID-19, and declared the outbreak as a pandemic in March 2020 [5]. 
As of 1 July 2020, the global COVID-19 cases have reached to 10,574,637 infected people, and 513,144 deaths [6]. Besides the global health implications [7], the COVID-19 outbreak has also had global socioeconomic and behavioural impacts. The pandemic has influenced human behaviours in a way that resulting in panic and over buying, and non-compliance with government restrictions [8]. On the other hand, the economic impact of COVID-19 is also immense as many national economies are in recession, and this will likely lead to a global financial crisis down the track [9].

In efforts to curb the pandemic, numerous scientific clinical trials and medical research have been undertaken, including the development of vaccines to treat the disease. Non-clinical measures-mainly the government interventions, e.g., social distancing policies, self-isolation, quarantines, movement control, travel restrictions, and lockdowns-are also adopted to control the further spread of COVID-19 [10].

The outbreak of COVID-19 has had a profound impact on the urban transport and mobility, where restrictions on travel and social gatherings have been announced to limit the spread [11]. For instance, as of 21 April 2020, the average mobility via public transit, on-foot, bike, and personal vehicles decreased to less than $10 \%$ in Vienna, London, New York, Madrid, Moscow, Singapore, and Milan [12]. In addition, home-based office and online education became other salient features of the global pandemic period [13]. This has turned our homes into a mixed-use place with home schooling space for the kids and work from home space for adults [14].

Meanwhile, the lockdown also exhibited an extraordinary demand for e-commerce for daily necessities and activities-e.g., groceries, medicines, clothes, ready foods. This has triggered an increased use of digital technologies and platforms, including social media, by the public. The increased data, via social media channels, generates an opportunity for authorities to benefit from such crowdsourced information to capture public perceptions to make well-informed decisions.

Especially over the past decade, social media has become one of the major data sources for academic research [15, 16], government departments, private and not-for-profit organisations, and individuals [17]. Besides, social media analytics can also benefit government authorities by capturing public opinions on and extracting relevant messages regarding the COVID-19 pandemic.

This paper aims to generate insights into how social media analytics can assist authorities in pandemicrelated policy decisions that are needed to ease or control pandemics. To achieve the research purpose, the study undertakes a social media analysis of geotagged tweets originated from Australian states and territories between 1 January and 4 May 2020.

\section{Literature background Epidemic and pandemic}

An epidemic is an outbreak of a disease that is not anticipated but spreads quickly and affects many people. It may particularly have a bigger toll on the underprivileged populations [18]. An example of epidemic would be the 2013-2016 Western African Ebola virus epidemic that took about 11,310 lives [19]. An outbreak can occur in a community, geographical area or several countries. In an epidemic, symptomatic cases are the predominant focus of treatment and usually represent the bulk of reported cases. Nonetheless, infected individuals who are asymptomatic yet infectious can be a critical factor in the spread of some pathogens [20].

A pandemic is a type of epidemic that relates to geographic spread and describes a disease-e.g., COVID19-that affects an entire country, continent or most parts of the world. An epidemic becomes a pandemic when it spreads over significant geographical areas and affects a large proportion of the population. A pandemic: (a) Affects a wider geographical area, and often worldwide; (b) Infects a larger number of people; (c) Is often caused by a new virus or a new strain of virus that has not circulated within people for a long time; (d) Is where people have little to no immunity against the virus and it spreads quickly; (e) Causes more deaths, and; (f) Often creates social disruption and economic loss. Examples of past pandemics include the Flu pandemic of 1968, HIV/AIDS pandemic, and Bubonic plague. The terms pandemic and epidemic are not used to indicate the severity of the disease, they only indicate the degree at which the disease is spreading [21].

\section{Stages of a pandemic spread Pre-concave}

The first stage (Stage 1) of the spread of a pandemic disease, e.g., COVID-19, is the pre-concave stage. This is when infected people travelled from affected countries into other countries. In Stage 1, only those who have travelled abroad test positive for the disease. The disease does not spread locally at this stage [22].

Some of the interventions at this stage, in the case of COVID-19, include: (a) Activating border measures; (b) Contact racing; (c) Cancel mass gatherings of people; (d) Staying at home if sick and have the symptoms; (e) Intensive testing for the virus, and; (e) Physical distancing encouragement [23]. 


\section{Concave-up}

The second stage (Stage 2) of the spread of a pandemic disease is the concave-up stage. This is the stage when local transmission occurs and its sources-e.g., originally infected patients who possibly had travel history to other already affected countries, are known and can be located. They would have come in close contact with the patients in situations such as family get-togethers, or occasions, where many people gather like in weddings and parties [22]. At this stage the virus might be contained, but the risk of community transmission still grows, and the number of new cases show increase.

Some of the interventions at this stage, in the case of COVID-19, include: (a) Maximising entry border measures; (b) Further restrictions on mass gatherings; (c) Physical distancing on public transport; (d) Limiting non-essential travels around the country; (e) Employer begin alternative ways of working-e.g., working from home, shifts, and so on; (f) Activating business contingency plans, and; (g) Remaining at home for people-particularly high risk groups [23].

\section{Linear}

The third stage (Stage 3) of the spread of a pandemic disease is the linear stage. At this stage, transmission rate of the disease has become stable-in other words, the number of new cases stay the same or change in a smaller variation in the linear stage.

Some of the interventions at this stage, in the case of COVID-19, include: (a) Traveling in areas of community transmission is limited; (b) Affected educational facilities closed; (c) Mass ways of working required and non-essential businesses are closed; (d) Non-face-to-face primary consultations; (e) Elective surgeries and procedures deferred, and; (f) Healthcare staff are reprioritised [23].

\section{Concave-down}

The fourth stage (Stage 4) of the spread of a pandemic disease is the concave-down stage. At this stage, the transmission rate of the disease shows a decline-in other words, the number of new cases decrease.

Some of the interventions at this stage, in the case of COVID-19, include: (a) Staying at home; (b) Closing educational facilities; (c) Closing all non-essential businesses; (d) Rationing of supplies and requisitioning of facilities; (e) Severe travel restrictions, and; (f) Major reprioritisation of healthcare services [23].

\section{Global suppression measures Flattening the curve}

During a pandemic situation, a tall and skinny curve of infected people to date is highly undesired (Fig. 1). This means a lot of people will get infected at once in a short period of time, because inadequate actions have been undertaken to prevent the disease from spreading. While most people might not get sick enough to be hospitalised, those who do could easily overwhelm the number of beds, equipment and healthcare staff available [24].

For instance, in the case of COVID-19, to this point, Australia has been highly successful in flattening the curve. The number of daily new COVID-19 cases in Australia is comparatively low (Fig. 2). This means, thus far, the spread of COVID-19 has been slowed down and Australian has built a capacity in the health system to

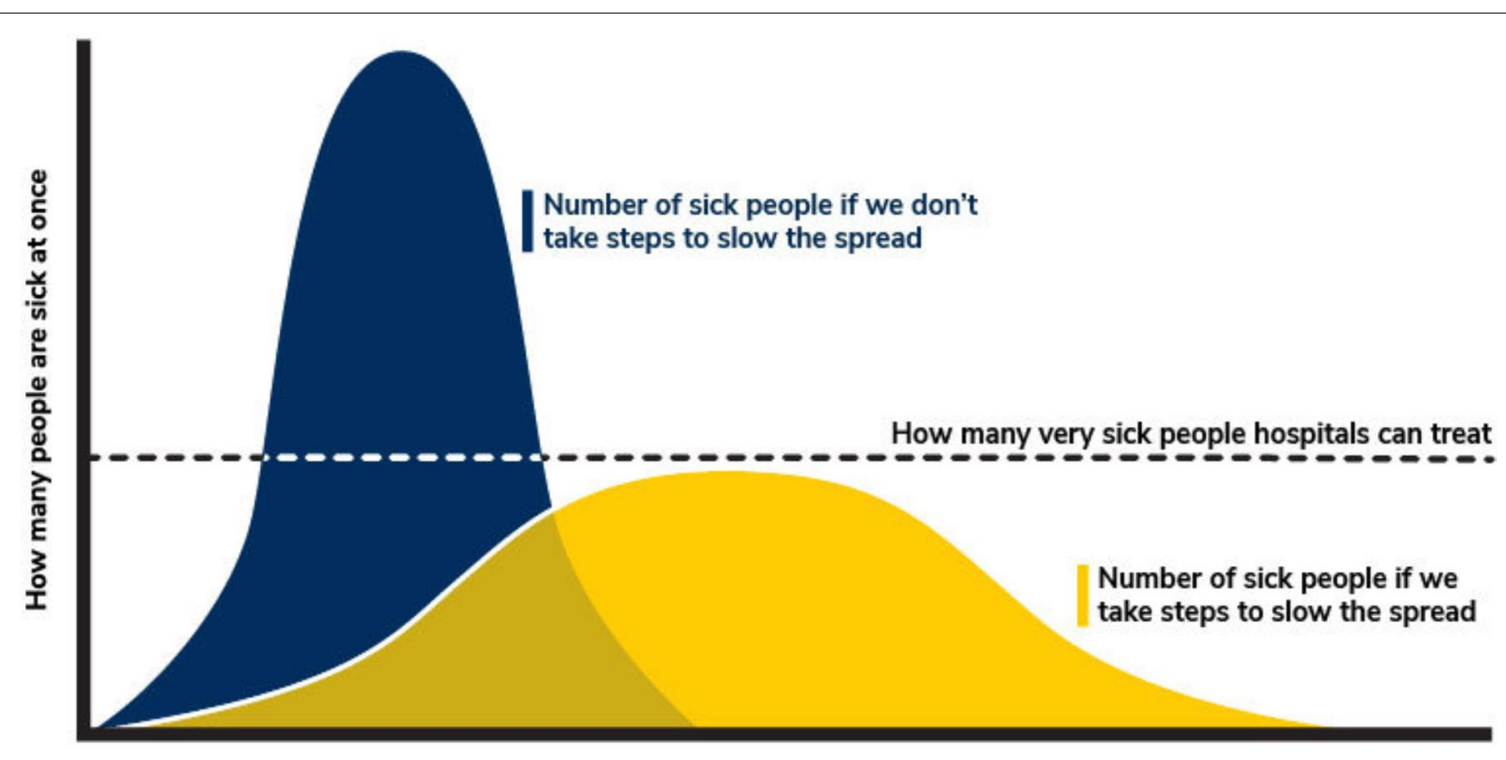

How long has the virus been spreading

Fig. 1 Flattening the curve function, derived from [24] 


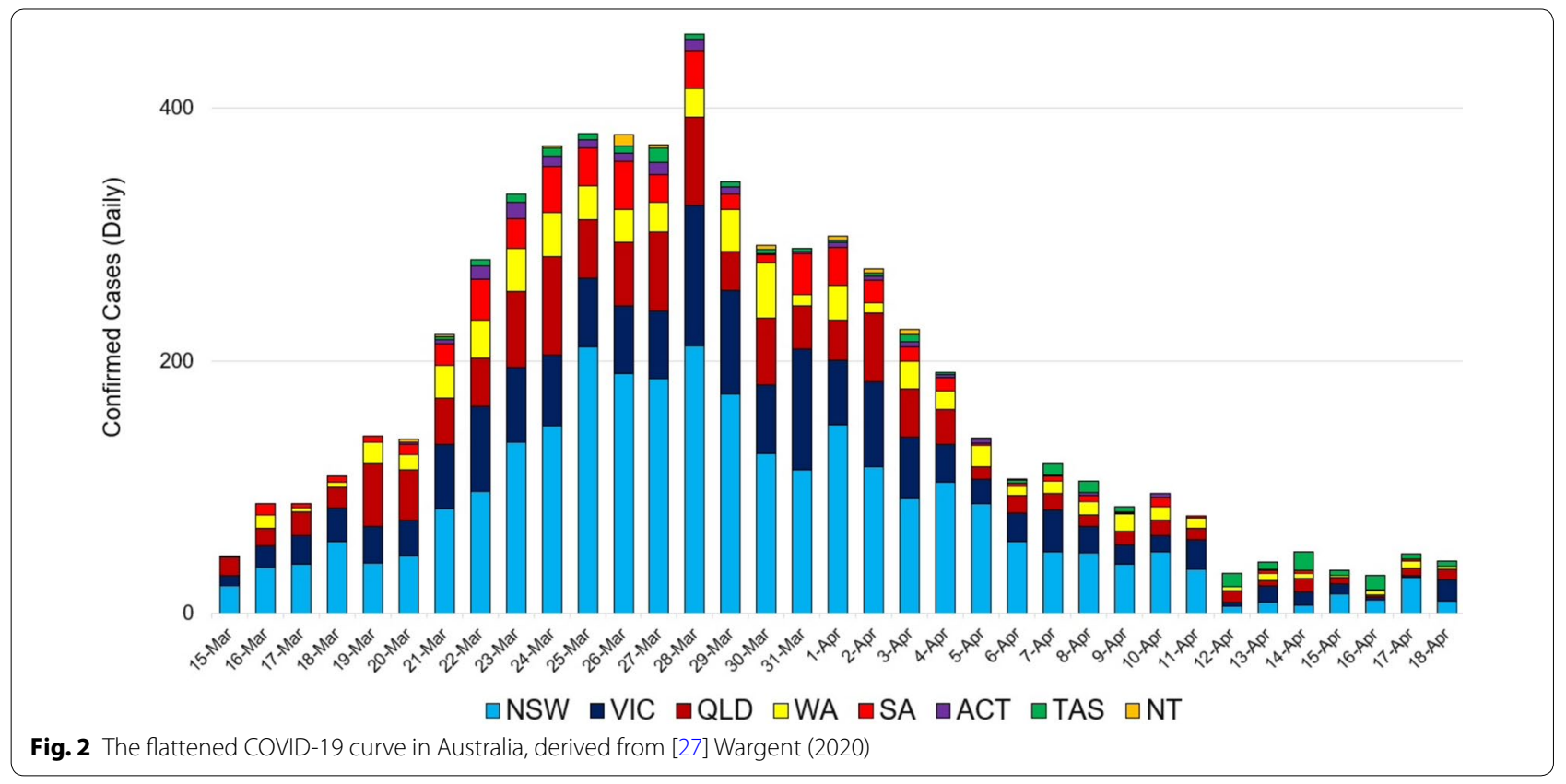

manage the impact of SARS-CoV-2. Nevertheless, the ultimate success depends on following government directives and maintaining the new community norm-e.g., social distancing, good hygiene practices, and using the COVIDSafe app [25]. As for the businesses, this also means taking the time to prepare and develop a plan to operate in a COVID-19 safe way to protect customers and employees [26].

\section{Hammer and dance}

The hammer In a pandemic situation, it is crucial to act quickly and aggressively. Hammering a pandemic, e.g., COVID-19, within a few weeks means it is controlled, and authorities are in much better shape to address its disruption. Applying a heavy hammer with strict social distancing measures can help immensely in controlling the outbreak within weeks [28].

The dance According to Pueyo's [28] graph, during the dance and in the case of COVID-19, it is crucial to go through the isolation and social distancing, ban large gatherings, test people properly, and also tighten up restrictions when needed.

The dance $R$ Some countries/cities/regions can experience outbreaks again, others may not for long periods of time. Depending on how cases evolve, it is needed to tighten up or relax social distancing measures. That is called the 'Dance of R', which is a dance of measures between getting our lives back on track and spreading the disease-e.g., balancing economic and health measures and outcomes (Fig. 3). During the hammer, the goal is to get $\mathrm{R}$ as close to zero, as fast as possible, to quench the pandemic. Once it moves into the dance, it is not need to be done anymore. The goal is to bring down the R value below 1 [28].

\section{Social media analytics}

Social media analytics are started to be used in the health sector these days. During the past decades, social media has redesigned the relationships in communities without any commercial objectives [29]. People become more expressive in social media than face to face direct discussions. Hence, the use of social media data for opinion mining, topic modelling, and sentiment analysis could benefit policy- and decision-makers to understand true public interest about health-related issues [30].

For instance, social media analytics were used to increase the efficiency of the health sector in different ways [31]. Some of the examples include: (a) Predictionsrelated to non-contagious diseases, e.g., heart disease mortality using psychological language used in tweets [32]; (b) Predictions-related to contagious diseases, e.g., the use of tweets to evaluate the disease activity and the US public perceptions during the influenza H1N1 pandemic [33]; (c) Governance in health, e.g., adapting social media in local health departments [34]; (d) Awareness raising, e.g., health information dissemination through social networks [35]; (e) Study on non-healthy addictions, e.g., college student's addiction to alcohol using Facebook and Twitter posts [36]; (f) Student education in the health sector, e.g., importance in introducing social media analytics to nursing curriculum [37], and; (g) Healthcare professionals-related issues, e.g., women 


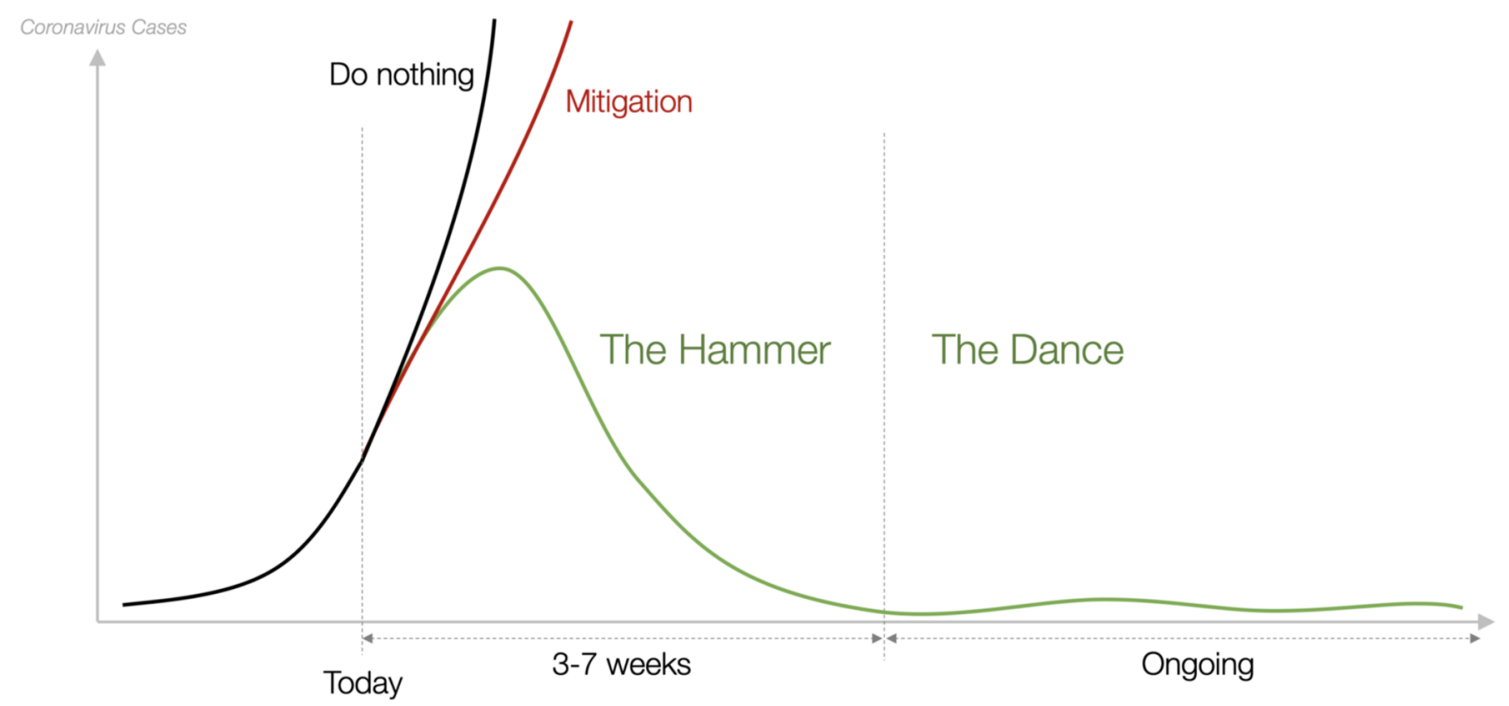

Fig. 3 The hammer and the dance derived from [28]

in the health sector [38]. Nevertheless, the use of social media analytics to increase the efficiency of community centric policy decisions during a pandemic is still an understudied area of research.

\section{Research design}

An empirical investigation is undertaken to answer the research question-How can social media analytics assist authorities in pandemic-related policy decisions? The investigation will help in understanding the behavioural tendencies of Australia's states and territories during the COVID-19 pandemic. The research steps include determining the case study, identifying the methodological approach, collection of data and execution of the analysis.

\section{Case study}

Australia is a suitable country to investigate the research question empirically for the following reasons. Australia is an advanced nation with a diverse culture that adapts the technological trends of the world, with the largest being, social media [39]. In 2018, 79\% of Australian's used social media and the average number of internet-enabled devices owned is 3.5 [40]. Like the rest of the world, Australia has been facing the COVID-19 disruption across all states and territories, adapting to social distancing restrictions, and altered ways of life to stop the spread. Between 1 January and 4 May 2020, Australia had a total of 6849 confirmed cases of COVID-19 and 96 related deaths [41] - as of 1 July 2020 these figures have reached to 7836 and 104 respectively. The states and territories with the most infections are coherent with population numbers, descending from NSW to VIC, QLD, WA, SA,
TAS, ACT and NT. Outbreaks have occurred in each state and territory in different ways, mostly relating to overseas travel/visitors. The largest outbreak occurred on the Ruby Princess cruise ship, which docked in Sydney allowing its passengers to leave [42].

\section{Methodological approach}

In the digital age, that is upon us, local community perceptions and suggestions about the changes happen in and around their environment are well reflected through social media messages [43]. A thorough analysis of such social media data will help to understand the community demands, issues, and reflections [44]. Accordingly, this study analysed geotagged Twitter social media messages circulated by the general public related to COVID-19 in Australia. Twitter has become the fastest growing social media platform source in the world. It also offers an Application Programming Interface (API) to researchers and practitioners to conduct analysis-such as the one undertaken in this study.

\section{Data and tools}

An ethical approval was obtained to obtain and analyse the social media posts of the Australian public. The first step, after the ethics clearance, in the methodology was a document survey to identify the actions taken by the Australian Governments (federal and state/territory) in response to the COVID-19 pandemic. This involved a collection of official government health department documents on COVID-19 in Australia-e.g., Pandemic Health Intelligence Plan at the federal level, and the 
Queensland Whole-of-Government Pandemic Plan at the state level. Such official documents were screened to identify 128 keywords (Table 1) to obtain/download related Twitter posts (a.k.a. tweets).

The second stage of the data collection involved the extraction of relevant Twitter information in the form of tweets. This is considered 'open data' and is publicly available to anyone. Tweets were extracted from the Digital Observatory of the Queensland University of Technology (QUT) (www.qut.edu.au/institute-for-futur e-environments/facilities/digital-observatory). Only the geotagged tweets were obtained as the locations of these posts were important for the analysis/study. Initially 96,666 geotagged tweets were collected using over pre-identified keywords related to COVID-19 symptoms, behaviours, precautions, and services. Some of the examples of symptom-related keywords include the text such as fever, flu, fatigue, cough and temperature. Examples of behaviour-related keywords include the text such as social distancing, isolation, quarantine, bored and working from home. Examples of precaution-related keywords include the text such as facemask, hand sanitiser and cover mouth. Examples of service-related keywords include the text such as health workers, salute and real heroes.

The third step is to clean the data. This procedure began with a data pre-processing stage, involving the removal of automated messages, irrelevant messages and URLs. The removal of these items was conducted using Arthur et al.s [45] process. The first of these was to remove automated messages with bot filtering, which discarded automated Twitter accounts that produced a high volume of tweets, affecting the data. The second step was relevance filtering, removing irrelevant tweets that contained keywords from the word bag (e.g., "the temperature is very high today"). The last was to remove URLs, which separated the URLs from the tweets so that a further analysis on the content of the URLs could be conducted. Excel software was used for the data cleaning processes. After filtering 35,969 geotagged tweets were selected to conduct the sentiment analysis. For this analysis an open access software for machine learning and data mining, known as WEKA, was employed-a software with a collection of visualisation tools. The Random Forest algorithm was used for data analysis and predictive modelling [46].

The fourth step in this process was to create a word bag to identify the community sentiments based on the filtered tweets. Accordingly, words such as dying, dead were classified as negative and the words, which express positive emotions such as enjoy, and happy were classified as positive sentiments. In total, 1183 words were used for this analysis; 588 of them with positive, and 595 with negative sentiments. In determining the word bags, the study used the following steps. Firstly, a random sample of 1000 tweets were inspected to identify the initial pool of word bags. Secondly, around $60 \%$ of total tweets (about 20,000 tweets) were screened to see the representation of the initial pool. Additional words were included in the word bags pool as a result of this screening. Thirdly, a randomised check of 500 tweets is conducted to confirm the words assigned in each sentiment category-i.e., positive and negative sentiments. Lastly, the list of 1183 words were finalised (588 positive, 595 negative). Examples of the word bags developed based on the analysed tweets are listed in Table 2.

The final step is to identify the frequently used words in each sentiment category. Accordingly, the frequently used words were identified by each state by each sentiment category. For this NVivo software was utilised-a qualitative data analysis software package.

\section{Results}

\section{General observations}

Out of 35,969 geotagged tweets analysed, about 63\% were negatively classified, and almost $37 \%$ were positively

Table 1 List of keywords 
Table 2 Word bag examples

\begin{tabular}{ll}
\hline Word bag & Example \\
\hline Positive & Adapt, best, better, cure, defeat, distance, \\
& discharge, exercise, facemask, fight, fun, \\
& handwash, healing, help, homedelivery, good, \\
& glad, great, hope, immunity, informative, joy, \\
& love, prepare, productive, protect, recover, \\
& release, safe, safety-first, stable, save, security, \\
& stay-home, support, survive, saving, treat, \\
& thank, vaccine, wash, well, welfare, win, wish, \\
& wonderful \\
Abuse, apocalypse, angry, anxiety, bad, cata- \\
strophic, contract, cough, crisis, danger, dead, \\
death, delay, die, disgusted, disease, ebola, \\
emergency, fail, fever, fighting, fired, hazard, \\
homeless, hurt, infect, kill, outbreak, pain, prob- \\
lem, recession, respiratory, resist, regret, scare, \\
sick, stress, stupid, violence, victim, vulnerable, \\
waste, worry, wtf
\end{tabular}

classified. Most of the negatively classified tweets were posted during the pre-concave stage (70\%). About $63 \%$ of the tweets circulated within the concave-up and linear stages carried negative sentiments. The concave-down stage had the least percentage of negatively classified tweets $(62 \%)$. Majority of the negatively classified tweets were tweeted from NSW, VIC, WA, and ACT people. Accordingly, in these states and territories, there were 9,885 more negatively classified tweets than the positively classified tweets.

The concave-up stage is the most critical period of a pandemic curve. During this period the number of confirmed cases rapidly increase within a shorter time period. Nonetheless, the Australian government developed 14 major responses to control the dispersion of COVID-19. Accordingly, on average, the concave-up stage of Australia lasted only for around 16 days and 29\% of the total tweets were circulated within this shorter time period.

\section{Suppression measures}

Transmission of COVID-19 can be categorised into (a) Small chains of transmission, and; (b) Large chains resulting in extensive spread. Countries such as Sri Lanka and New Zealand took strong measures at the earliest, and ended up in small chains of transmission. The countries that have not taken strong measures at the earliest ended up in large chains of transmission such as USA and Brazil [47].

Australia took strong actions to fight with this new pandemic. On 25th January 2020, the first COVID-19 patient was confirmed, who had flown to Melbourne from Guangdong Province of China on 19 January 2020 [48]. On 1 February 2020, Australian government blocked
China arrivals to the country. Since then, until 4 May 2020, Australian government has developed 14 major responses-so-called pandemic responses-to control spreading the COVID-19 in Australia, and another 7 major responses-so-called economic responses-to address the economic downturn [49]. These 21 major governmental responses are listed in Table 3, and also marked in Figs. 4, 5, 6, 7, 8, 9, 10, 11 and 12.

Figure 4 shows the dispersion of confirmed COVID19 cases, deaths, the tweets circulated in Australia and the responses undertaken by the Australian government to stop the spreading of COVID-19. As shown in Fig. 4, the number of tweets and the number of confirmed cases have a positive relationship with a statistical correlation of 0.72 at 0.05 significance level. This shows that the number of tweets changed according to the number of confirmed cases. Furthermore, Fig. 4 emphasised that 21 major governmental responses (14 health and 7 economic) to the pandemic undoubtedly have led to the flattening of the COVID-19 pandemic curve of Australia.

When governments respond to a pandemic, their economy also get affected. Hence, taking strong economic responses simultaneously with pandemic responses is important to battle a pandemic effectively [50]. Among such responses, community welfare needs to be given priority as people go out of jobs due to unprecedented pandemic responses such as social distancing, selfisolation, and restriction to mass gatherings. As listed Table 3, Australian government introduced 7 major economic responses within the study period. They were oriented towards delivering funds to the financially struggling people, and unemployed. Additionally, the federal government decided to reduce social security deeming rates. Accordingly, on 1 May 2020, the upper and lower deeming rates were $2.25 \%$ and $0.25 \%$ respectively. These reductions created a low interest environment, which benefitted around 900,000 income support recipients, and around 565,000 pensioners.

Albeit, the community perceptions towards such 'radical' and 'unprecedented' measures need to be reviewed closely and thoroughly. Most significantly, during pandemic situations, where social distancing is a must, social media analytics can help policy- and decision-makers to screen community behaviours without reaching the community directly. Table 4 contains the most frequent used across all the four stages. In all of the phases, the words such as coronavirus, covid, covid-19, covidaus, pandemic, virus, and outbreak were used and repeated extensively. For that reason, such words were not included in Table 4 .

Figures 5, 6, 7, 8, 9, 10, 11 and 12 illustrate the distribution of positively and negatively classified tweets in all Australian states and territories-along with the number of infection cases and deaths. In Australia, the only 
Table 3 Major responses undertaken by the Australian government to combat COVID-19

\begin{tabular}{|c|c|c|}
\hline No & Date & Response \\
\hline 1 & 01/02/2020 & Blocked China arrivals ${ }^{\mathrm{a}}$ \\
\hline 2 & 29/02/2020 & Blocked Iran arrivals ${ }^{\mathrm{a}}$ \\
\hline 3 & 05/03/2020 & Blocked South Korea arrivals ${ }^{\mathrm{a}}$ \\
\hline 4 & $11 / 03 / 2020$ & Blocked Italy arrivals ${ }^{a}$ \\
\hline 5 & $13 / 03 / 2020$ & Outdoor gatherings limited to 500 persons ${ }^{\mathrm{a}}$ \\
\hline 6 & 16/032020 & Self-isolation for overseas travellers, cruise ships blocked for 30 days $^{\mathrm{a}}$ \\
\hline 7 & 18/03/2020 & Indoor gatherings limited to 100 persons $^{\mathrm{a}}$ \\
\hline 8 & 19/03/2020 & Borders closed to non-citizens and residents ${ }^{\mathrm{a}}$ \\
\hline 9 & 20/03/2020 & Started to pay JobSeeker payments ${ }^{b}$ \\
\hline 10 & 23/03/2020 & Pubs/clubs closed, restaurants take-away only ${ }^{a}$ \\
\hline 11 & 24/03/2020 & Ban on Australians travelling overseas ${ }^{a}$ \\
\hline 12 & 25/03/2020 & Temporarily reduced minimum drawdown rated for superannuation ${ }^{b}$ \\
\hline 13 & 26/03/2020 & Expanded testing criteria ${ }^{a}$ \\
\hline 14 & 28/03/2020 & Mandatory isolation in hotels for all travellers ${ }^{\mathrm{a}}$ \\
\hline 15 & 30/03/2020 & Outdoor/indoor gatherings two persons only ${ }^{\mathrm{a}}$ \\
\hline 16 & $31 / 03 / 2020$ & Provided payments of $\$ 750$ to social security, veteran and other income support recipients ${ }^{b}$ \\
\hline 17 & 26/04/2020 & The COVIDSafe App is released ${ }^{\mathrm{a}}$ \\
\hline 18 & 27/04/2020 & Expanded eligibility to income support payments ${ }^{\mathrm{b}}$ \\
\hline 19 & 27/04/2020 & Paid the time restricted COVID-19 supplement of $\$ 500$ which paid per fortnight ${ }^{b}$ \\
\hline 20 & 01/05/2020 & Increased transfer payments from reduced deeming rates ${ }^{b}$ \\
\hline 21 & 04/05/2020 & Started to pay JobKeeper payments ${ }^{\mathrm{b}}$ \\
\hline
\end{tabular}

a Health response

${ }^{b}$ Economic response

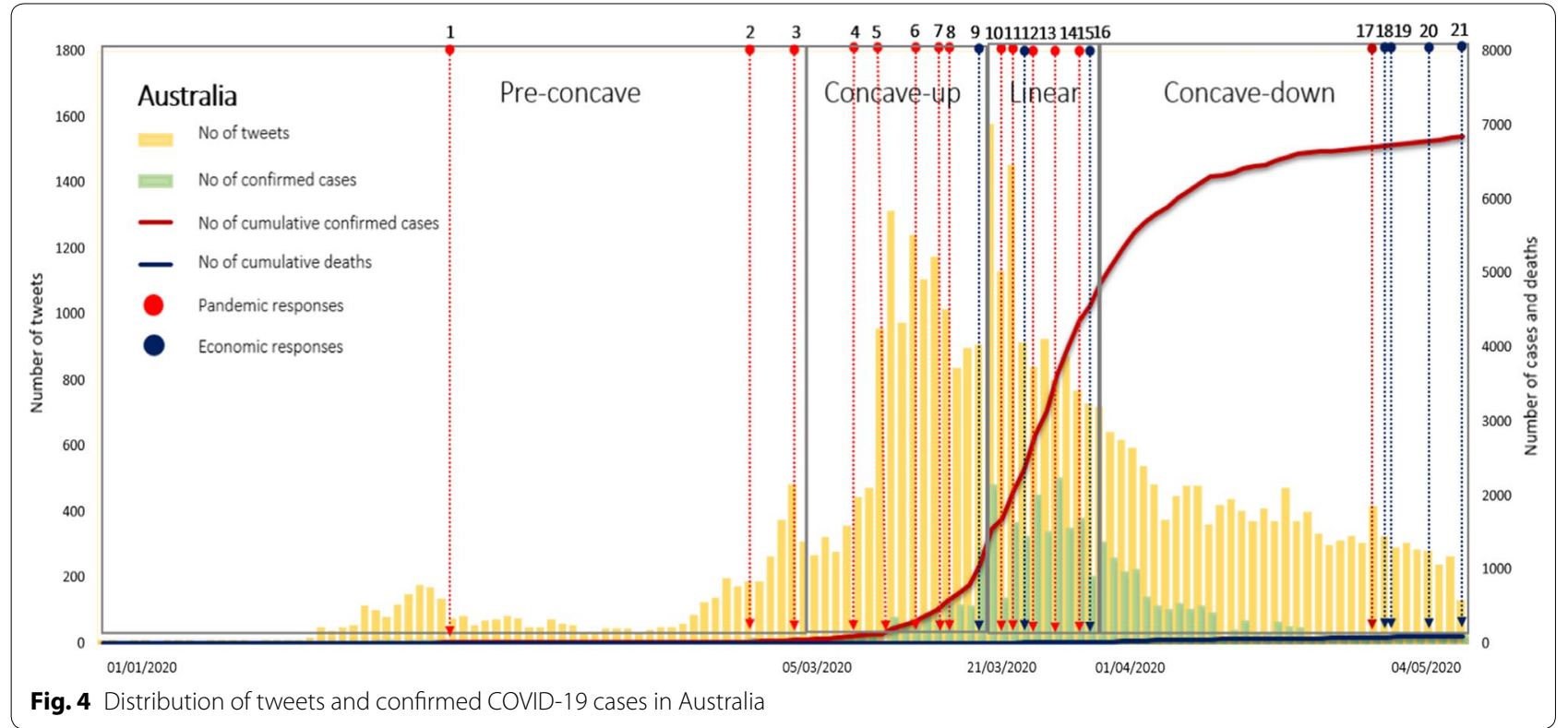

state/territory that did not experienced the COVID-19 concave-up stage was NT (Fig. 12). This is due to successful execution of health responses in line with the hammer and dance approach (presented in the literature background section). In the case of VIC, the last week of the analysis (27 April to 04 May 2020) has shown an increase in the confirmed cases. Hence, that week was registered as the second linear stage (Fig. 5). This is an 

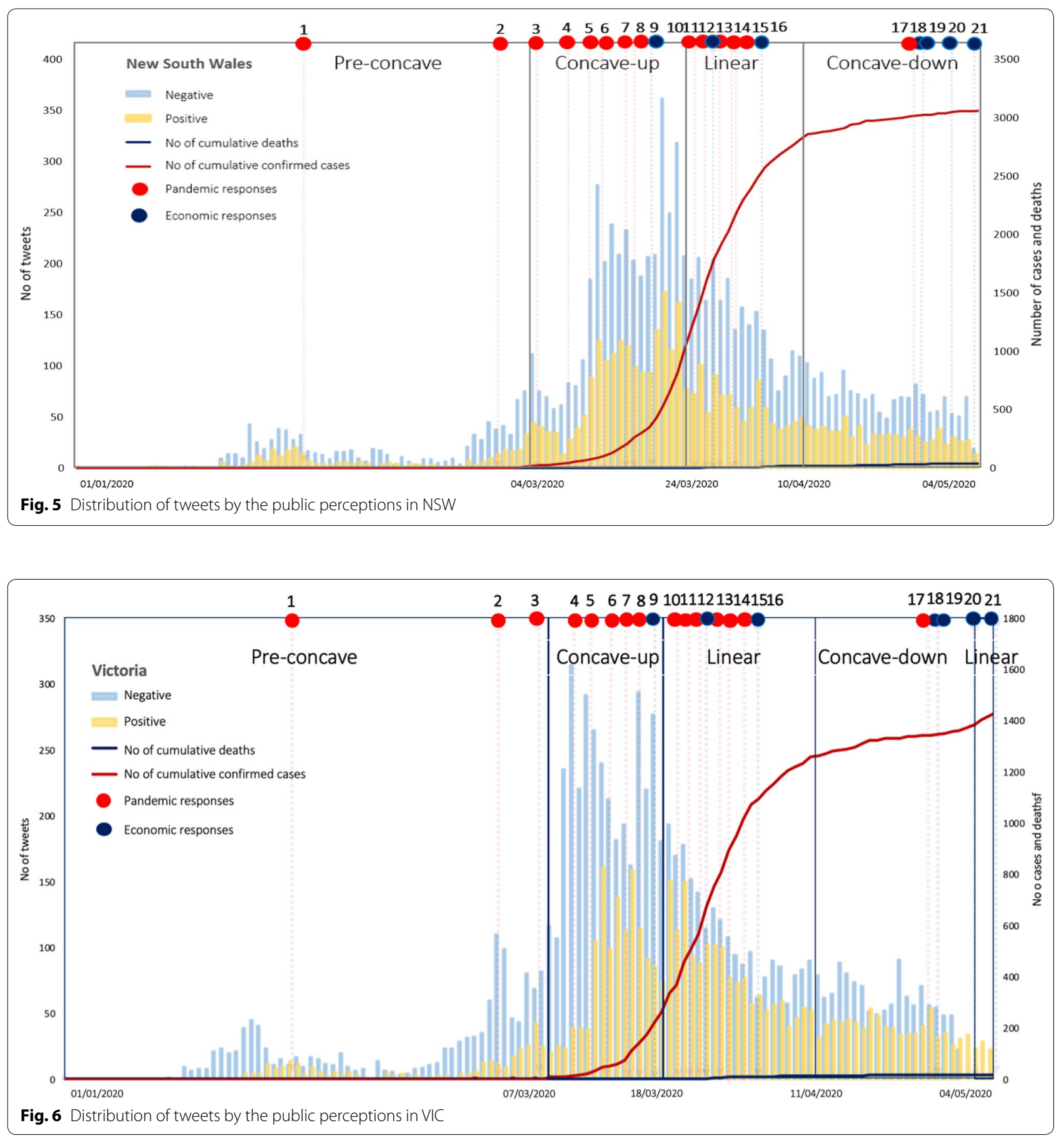

example of pandemics not having a consistent pattern. Without the right responses and interventions, a second wave could be experienced.

In all figures presented, there was a small twitter peak in the pre-concave stage, when there was no significant number of confirmed cases. Such unusual twitter peaks provide an indication of a possible disaster, an unusual behaviour in the environment, or a special community demand [51-53]. Thus, mining the perceptions of the general public via social media platforms during a pandemic is essential for policyand decision-makers to take people-centric decisions, 

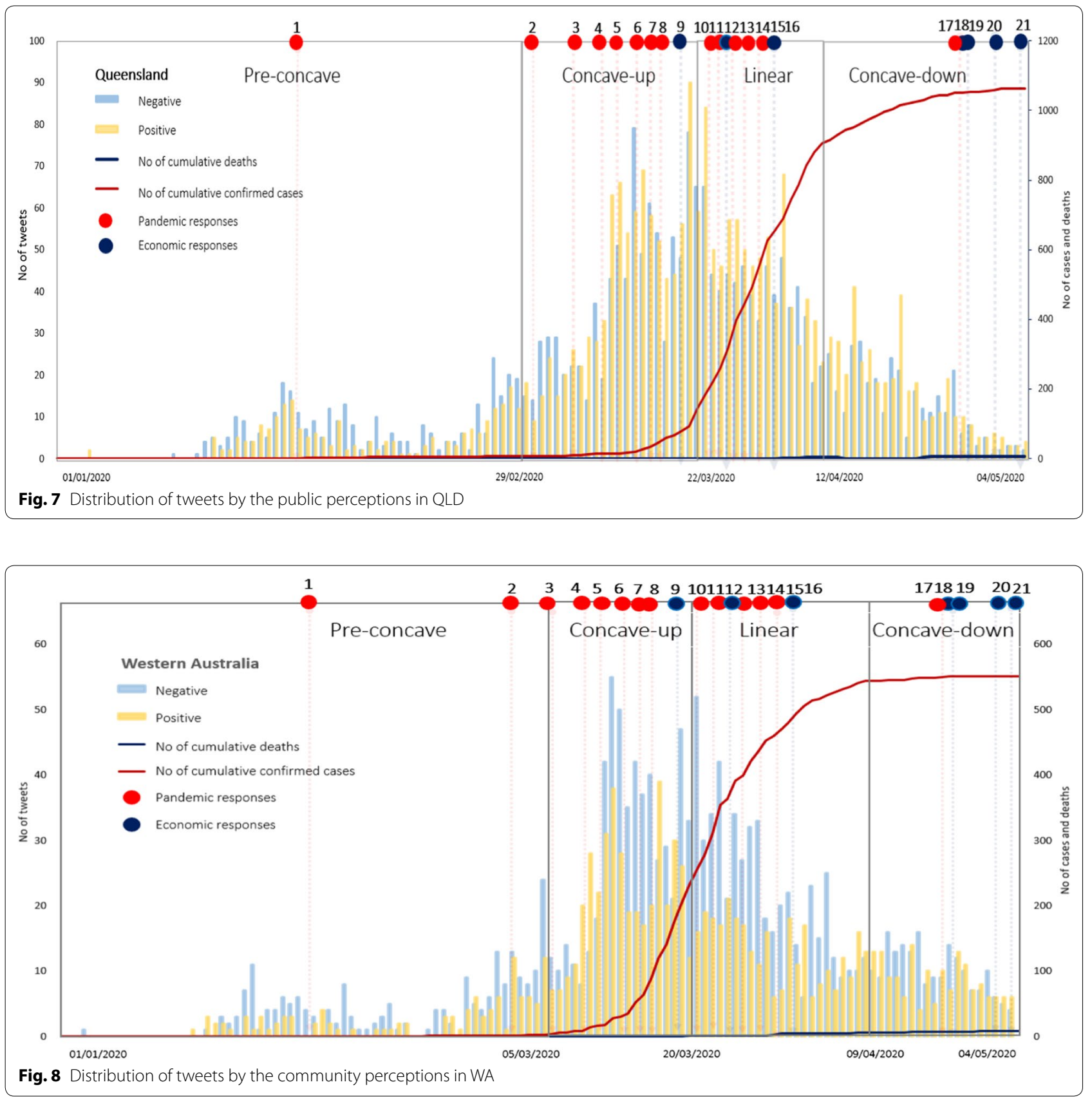

while adhering to the regulations of social distancing and so on.

\section{Positive community perceptions Pre-concave}

Only $30 \%$ of the total tweets circulated within this stage carried positive perceptions. In NT, the number of positive tweets $(n=105)$ in this stage was high compared to the number of negative tweets $(n=65)$. By contrast, TAS,
SA, and QLD had more negative tweets than positive ones, though their difference is comparatively small.

Among the tweets circulated in NT, the words of people $(0.73 \%)$, health $(0.55 \%)$, good $(0.55 \%)$, family, government $(0.45 \%)$, and learn $(0.41 \%)$ were popular among the positively classified tweets. People from TAS used the words of people $(2.09 \%)$, response $(1.26 \%)$, masks $(0.84 \%)$, save $(0.84 \%)$, toilet $(0.84 \%)$, paper $(0.84 \%)$, care $(0.42 \%)$, resources $(0.42 \%)$ frequently in tweets with positive sentiments. In SA people used testing (1.09\%), 

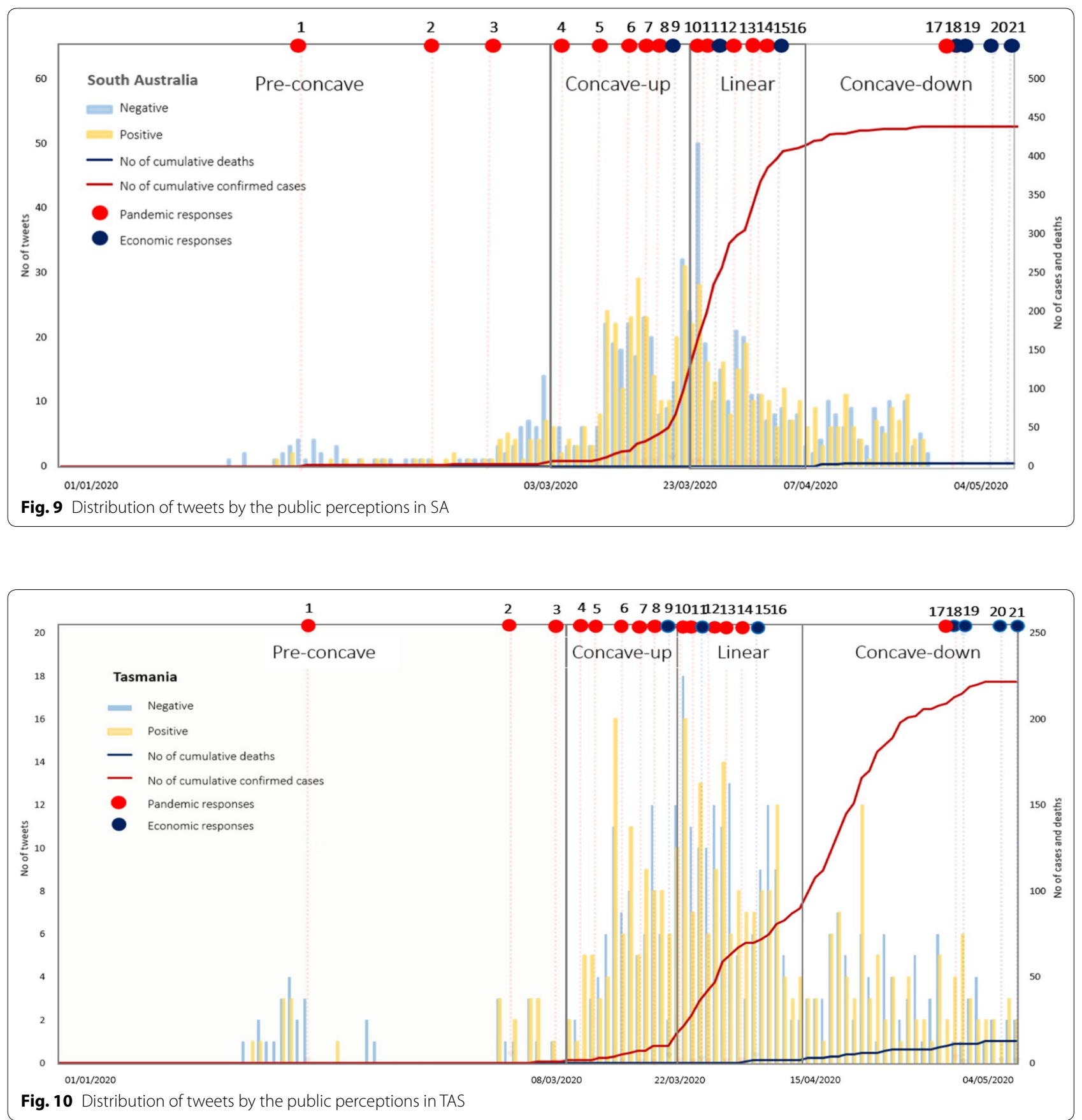

management $(0.9 \%)$, health $(0.81 \%)$, shutdown $(0.98 \%)$, people $(0.65 \%)$, toilet $(0.58 \%)$, and help $(0.45 \%)$ often to express their positive attitudes. People from QLD frequently used health $(0.91 \%)$, good $(0.88 \%)$, quarantine $(0.84 \%)$, test $(0.7 \%)$ and reaction $(0.46 \%)$ words to express their positive ideas. Table 5 shows the example tweets circulated related to the abovementioned words.

NSW, VIC, WA and ACT had comparatively much fewer tweets with positive sentiments. Nevertheless, in general the words such as survive, health, good, young, support, protect, care, and family were frequent among the positively classified tweets circulated within the aforesaid states/territories.

\section{Concave-up}

Around $37 \%$ of the total tweets circulated within this stage carried positive sentiments. TAS, SA, and QLD had more positive tweets compared to other states and 

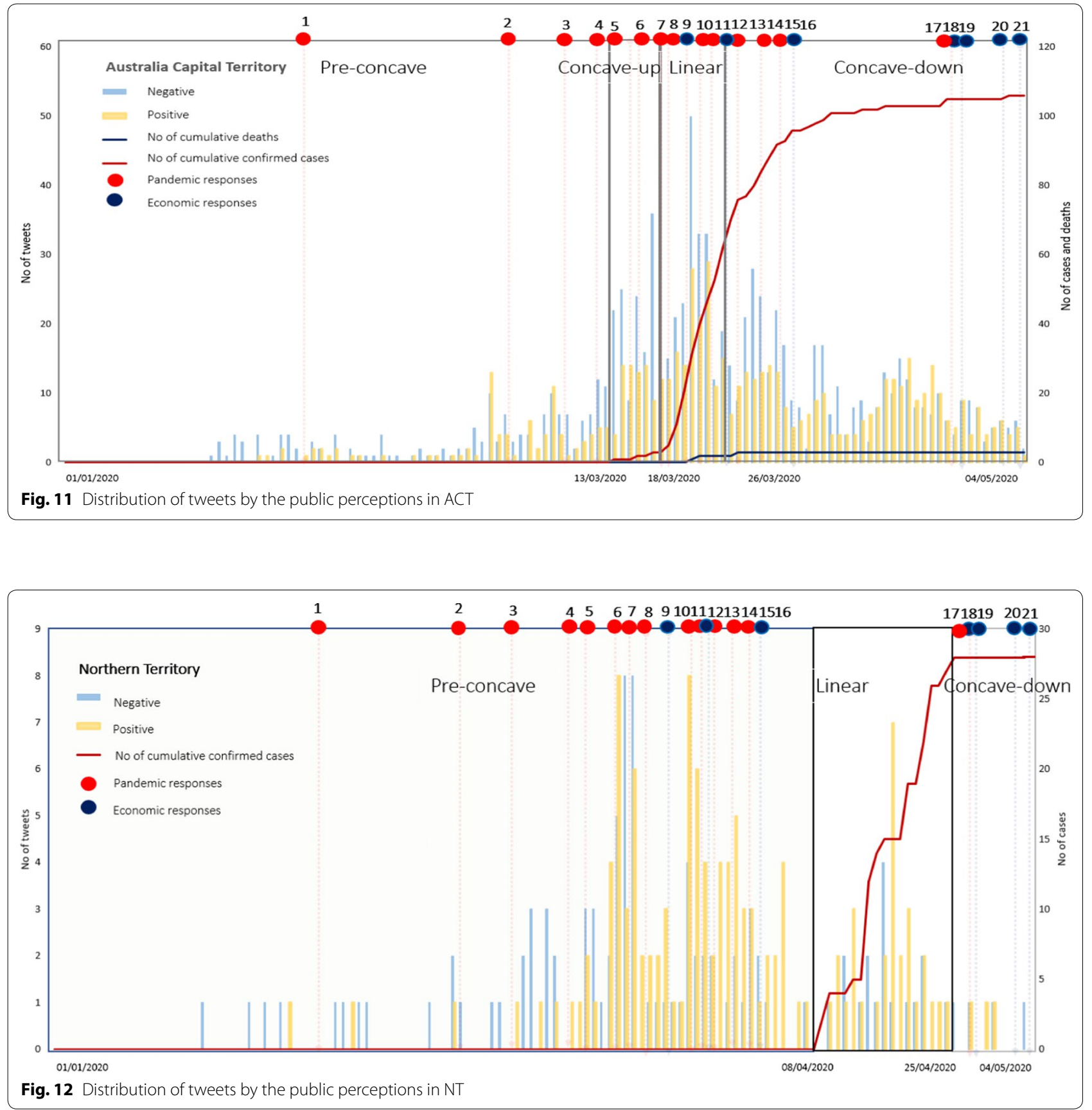

territories. NT did not go through the concave-up stage due to the low number of confirmed COVID-19 cases mainly because NT practiced the hammer and dance successfully, where the identified small COVID-19 patient clusters were strictly hammered by the enacted measures.

People from TAS repeatedly used the words of positive sentiments such as good (0.92\%), block (0.74\%), immediate $(0.65 \%)$, health $(0.63 \%)$, care $(0.56 \%)$, ban
(0.51\%), support $(0.42 \%)$, and prepare $(0.41 \%)$. The tweets circulated within SA with positive sentiments mostly carried the words of health $(0.99 \%)$, shutdown $(0.98 \%)$, people $(0.65 \%)$, expect $(0.57 \%)$, distance $(0.57 \%)$, enjoy $(0.53 \%)$, isolate $(0.45 \%)$, and help $(0.45 \%)$. The words such as people $(0.78 \%)$, practice $(0.75 \%)$, health $(0.57 \%)$, care $(0.41 \%)$, stay $(0.41)$, and expect $(0.4 \%)$ were popular among the tweets with positive sentiments circulated in QLD. Table 6 shows 
Table 4 The most frequent positive and negative words of pre-concave, concave-up, linear, and concave-down stages in all states

\begin{tabular}{|c|c|c|}
\hline & Positive & Negative \\
\hline Pre-concave & $\begin{array}{l}\text { People }(0.89 \%) \text {, health }(0.63 \%) \text {, test }(0.49 \%) \text {, government }(0.47 \%) \text {, } \\
\text { care }(0.46 \%)\end{array}$ & $\begin{array}{l}\text { People }(0.87 \%) \text {, cases }(0.74 \%) \text {, travel }(0.69 \%) \text {, death }(0.55 \%) \text {, } \\
\text { outbreak }(0.5 \%) \text {, spread }(0.4 \%)\end{array}$ \\
\hline Concave-up & $\begin{array}{l}\text { People }(0.81 \%), \text { good }(0.63 \%) \text {, help }(0.53 \%) \text {, stay }(0.47 \%) \text {, support } \\
(0.4 \%)\end{array}$ & People $(0.41 \%)$, cases $(0.45 \%)$ \\
\hline Linear & People $(0.75 \%)$, test $(0.43 \%)$, home $(0.43 \%)$ & People $(0.78 \%)$, home $(0.4 \%)$ \\
\hline Concave down & $\begin{array}{l}\text { Safe }(0.97 \%) \text {, start }(0.8 \%) \text {, people }(0.67 \%) \text {, work }(0.66 \%) \text {, test } \\
(0.58 \%) \text {, days }(0.56 \%) \text {, support }(0.52 \%) \text {, stay }(0.46 \%) \text {, health } \\
(0.42 \%) \text {, government }(0.41 \%)\end{array}$ & $\begin{array}{l}\text { People }(0.69 \%) \text {, deaths }(0.45 \%) \text {, suffer }(0.42 \%) \text {, work }(0.4 \%) \text {, home } \\
(0.4 \%)\end{array}$ \\
\hline
\end{tabular}

Table 5 Example tweets with positive sentiments circulated within pre-concave stage

\begin{tabular}{|c|c|c|c|}
\hline Date and time & State & Keyword & Exemplar tweet \\
\hline 18/04/2020 05:31 & SA & Health & $\begin{array}{l}\text { Deloitte develops digital accelerator healthcare systems for communities to address covid19 crisis } \\
\text { \#exphealthcare }\end{array}$ \\
\hline 30/03/2020 13:27 & VIC & Family & Coronavirus wedding, Melbourne family allowed to celebrate! \\
\hline 16/03/2020 08:07 & SA & Shutdown & The Australian arts and events sector MUST be supported during the coronavirus shutdown \\
\hline 23/01/2020 22:46 & QLD & Tests & Here in Queensland to date we've already tested 4 people all 4 came back negative 2 waiting on results \\
\hline 07/03/2020 14:27 & TAS & Resources & $\begin{array}{l}\text { At work we've put together some coronavirus info \& resources to support people living with disability. Please } \\
\text { feel free to share with anyone it may help }\end{array}$ \\
\hline
\end{tabular}

Table 6 Example tweets with positive sentiments circulated within concave-up stage

\begin{tabular}{|c|c|c|c|}
\hline Date and time & State & Keyword & Exemplar tweet \\
\hline 17/03/2020 04:47 & TAS & Shut & $\begin{array}{l}\text { PM lockdowns the country Australian shut turn weeks actions managed essential services supply chains pro- } \\
\text { tected coronavirus impact for months \#auspol }\end{array}$ \\
\hline 05/04/2020 07:16 & SA & Distance & $\begin{array}{l}\text { Day thirteen covid isolation keeping distance. casual Thursday catch covid19 create with every breath custom } \\
\text { we make it \#supportsmallbusiness \#sunstatejewellers \#sunstate\# jewellers }\end{array}$ \\
\hline 09/02/2020 06:46 & QLD & Enjoy & Enjoying Netflix series pandemic moment interesting watch reiterated fact antivaxxers insane \#quickdetector \\
\hline 14/03/2020 12:09 & TAS & Practice & Support promoting positive mental health wellbeing practices pandemic news climate greatly appreciated \\
\hline 21/03/2020 21:44 & SA & Health & $\begin{array}{l}\text { Patients declared, corona virus south Australia declared safe released \#hospital \#happy \#response \#senseurgency } \\
\text { \#australian \#healthcare \#industry }\end{array}$ \\
\hline
\end{tabular}

the example tweets circulated related to the abovementioned words.

NSW, VIC, WA, and ACT had lesser tweets with positive sentiments during this stage compare to the other states/territories. Nevertheless, the words such as people, health, good, motivate, care and help were plural in the limited number of positively classified tweets in the abovementioned states/territories.

\section{Linear}

About $37 \%$ of the total tweets circulated in this stage were classified as tweets with positive sentiments. This is the period, when the number of daily reported cases gradually increase at an equal/slower rate than in the concave-up stage. Consequently, more positive tweets can be expected from this stage. Similarly, QLD, SA, TAS, and NT had more tweets with positive sentiments than other regions.

The most frequently used words in QLD were, lives $(0.95 \%)$, prevent $(0.72 \%)$, online $(0.72 \%)$, distance $(0.6 \%)$, support $(0.54 \%)$, advice $(0.48 \%)$, and family $(0.48 \%)$. Tweets with positive sentiment values circulated in SA included more words such as people (1.1\%), lives $(0.79 \%)$, advantage $(0.71 \%)$, health $(0.65 \%)$, government $(0.52 \%)$, stay $(0.46 \%)$, quarantine $(0.43 \%)$, family $(0.42 \%)$, and care $(0.4 \%)$. People form TAS had more tweets in this phase related to the words of people $(0.78 \%)$, health $(0.59 \%)$, check $(0.44 \%)$. NT community used the words of crisis $(0.95 \%)$, days $(0.72 \%)$, distance $(0.6 \%)$, government $(0.48 \%)$, and people $(0.48 \%)$. Table 7 
Table 7 Example tweets with positive sentiments circulated within linear stage

\begin{tabular}{|c|c|c|c|}
\hline Date and time & State & Keyword & Exemplar tweet \\
\hline 29/02/2020 21:19 & QLD & Online & $\begin{array}{l}\text { Social media teachers deliver classes online, countries covid focus appears delivery content students dem- } \\
\text { onstrating evidence learning keen hear thoughts }\end{array}$ \\
\hline 28/03/2020 09:20 & SA & Family & $\begin{array}{l}\text { Kind positive happy message family quarantine \#stayhome positive kind happy documentary covid19 } \\
\text { coronavirus \#SA australia \#adelaide \#adelaide \#australia }\end{array}$ \\
\hline 15/03/2020 00:01 & QLD & Prevent & $\begin{array}{l}\text { Maths extensive social distancing read quarantine preventative purposes waiting sick effective strategy } \\
\text { flatten covid19 curve }\end{array}$ \\
\hline 14/04/2020 01:00 & NT & Government & Australian government launches coronavirus publicity blitz country runs testing kits \\
\hline 27/03/2020 08:20 & TAS & Check & Remember folks, libraries closed free ebooks library check library's website \\
\hline
\end{tabular}

displays the example tweets related to the abovementioned words.

Although NSW, VIC, WA and ACT had more negative tweets in this stage, the words such as help, good, safe, family, global, study, and health were popular among the positively classified tweets.

\section{Concave-down}

About $38 \%$ of the total tweets circulated within this stage carried positive sentiment values. QLD, NT, TAS, and SA had a few more tweets with positive sentiment values than those with negative sentiment values. People $(0.74 \%)$, safe $(0.71 \%)$, test $(0.66 \%)$, fund $(0.64 \%)$, support $(0.64 \%)$, app $(0.43 \%)$, invest $(0.41 \%)$, care $(0.4 \%)$, and isolate $(0.4 \%)$ were the mostly used words in the positively classified word category in QLD. Positively classified tweets circulated within this period in NT carried words such as approach $(4.76 \%)$, good $(4.76 \%)$, herd (4.76\%), and immunity (2\%). People from TAS used government $(0.86 \%)$, attitude $(0.74 \%)$, app $(0.72 \%)$, family $(0.58 \%)$, distance $(0.43 \%)$, vaccine $(0.43 \%)$, and safe $(0.41 \%)$. SA people used the words such as good $(0.92 \%)$, app $(0.61 \%)$, track $(0.6 \%)$, normal $(0.57 \%)$, vaccine $(0.54 \%)$, claim $(0.5 \%)$, and days $(0.46 \%)$ often in the tweets with positive sentiments. Sample tweets circulated related to the frequently used positive sentiments are given in Table 8 .

NSW, VIC, WA, and ACT also had comparatively a low number of positively classified tweets related to this stage. Among them, the words such as tests, stay, support, health, learn, people, help, good and school were popular.

\section{Negative community perceptions Pre-concave}

Almost $70 \%$ of the total tweets circulated within this stage carried negative sentiments. VIC, NSW, ACT, and WA had more negative tweets than positive ones (Fig. 7). VIC confirmed the first Australian COVID-19 patient on 25 January 2020 [54]. Since then, confirmed cases emerged across the state. The words such as arrival $(1.16 \%)$, immediate $(0.72 \%)$, cases $(0.67 \%)$, paper $(0.62 \%)$, catch $(0.5 \%)$, toilet $(0.5 \%)$, commodities $(0.5 \%)$, dead $(0.8 \%)$, and spread $(0.43 \%)$ were plural among the negatively classified tweets in VIC. NSW community used the words related to suffer $(0.94 \%)$, fail $(0.73 \%)$, cases $(0.67 \%)$, and death $(0.47 \%)$ frequently in the tweets shared. Tweets classified as negative in ACT included words such as die $(1.06 \%)$, cases $(0.81 \%)$, arrive $(0.69 \%)$, and days $(0.52 \%)$. The words such as hard (1.56\%), contract (1.51\%), die $(0.93 \%)$, buy $(0.67 \%)$, work $(0.59 \%)$, affect $(0.46 \%)$, panic $(0.4 \%)$ were often used in WA. Sample tweets circulated related to the frequently used negative sentiments are given in Table 9.

Although QLD, SA, TAS, and NT had more positive tweets than negative ones in this stage, the words such as spread, risk, infect, flu, work, China, business, death, and panic were common among the negatively classified tweets.

Table 8 Example tweets with positive sentiments circulated within concave-down stage

\begin{tabular}{|c|c|c|c|}
\hline Date and time & State & Keyword & Exemplar tweet \\
\hline 24/04/2020 06:36 & TAS & App & Fully understand downloading covidsafe app doesn't automatically prevent virus, but it's a good initiative \\
\hline $12 / 04 / 202014: 40$ & SA & Normal & Covid19 permanently normalise virtual technologies judging zoom meetings \\
\hline 23/04/2020 22:41 & TAS & Vaccine & $\begin{array}{l}\text { AAMRIS members projects progress relating covid } 19 \text { covering vaccines drug trials diagnostics screening } \\
\text { tests mental health indigenous health }\end{array}$ \\
\hline 11/04/2020 15:46 & QLD & Fund & $\begin{array}{l}\text { Scott Morrison pressed abc730 virgin australia's request 14b loan bailout pm suggests industry superan- } \\
\text { nuation funds to super fund step fed govt \#abcnews \#twuaus \#coronavirus \#virginaustralia }\end{array}$ \\
\hline 29/04/2020 04:48 & NT & Immunity & Pretty great idea herd immunity approach controlling spread virus \\
\hline
\end{tabular}


Table 9 Example tweets with negative sentiments circulated within pre-concave stage

\begin{tabular}{|c|c|c|c|}
\hline Date and time & State & Keyword & Exemplar tweet \\
\hline 02/03/2020 02:12 & VIC & Fail & $\begin{array}{l}\text { Making sickening joke of Morrisons plan he has on potential carriers of coronavirus looking tends be part of } \\
\text { widespread failure of LNP While AFP are looking all wrong places auspol }\end{array}$ \\
\hline 29/01/2020 08:58 & NSW & Suffer & $\begin{array}{l}\text { Interesting. Last heard some people had virus were reinfected afterwards Apparently did not develop an immu- } \\
\text { nity } 2 \text { virus Inoculate supposed trigger the effect yet hears sufferers developed any type immunity reinfect } \\
\text { may wrong }\end{array}$ \\
\hline 30/03/2020 00:06 & VIC & Arrival & $\begin{array}{l}\text { Need to assure that the community evacuees from diamond princess cruise be heavily screened before their } \\
\text { arrival }\end{array}$ \\
\hline 28/02/2020 02:45 & ACT & Dead/die & $\begin{array}{l}\text { Media bull shit Corona Get Common cold die FFS peoples together think percentages not raw numbers wealthy } \\
\text { worry does homelessness poverty pure desperation fellow countrymen not move more }\end{array}$ \\
\hline 25/01/2020 05:53 & WA & Hard & Moneys come hard during pandemic \\
\hline
\end{tabular}

\section{Concave-up}

During this phase the number of tweets with negative sentiments $(63 \%)$ were significantly high compared to the number of positive tweets. For instance, the number of negatively classified tweets in NSW and VIC were almost the twice of the positively classified tweets. Besides, both ACT and WA had more negative tweets than positively classified tweets circulated within this stage.

Most of the negatively classified tweets circulated within NSW carried the words such as cause (1.26\%), work $(1 \%)$, fail $(0.76 \%)$, travel $(0.76 \%)$, immediate $(0.68 \%)$, hard $(0.64 \%)$, cases $(0.57 \%)$, control $(0.48 \%)$, collapse $(0.42 \%)$, and death $(0.4 \%)$. Within the tweets from VIC, arrival $(1.41 \%)$, travel $(0.87 \%)$, immediate $(0.7 \%)$, cases $(0.49 \%)$, and lives $(0.41 \%)$ were the most popular. People from ACT used more words such as die (1.39\%), affect $(0.51 \%)$, mortgage $(0.43 \%)$, and suffer $(0.42 \%)$. The words such as die $(1.18 \%)$, work $(0.77 \%)$, hard $(0.72 \%)$, check $(0.65 \%)$, suffer $(0.5 \%)$ and cases $(0.42 \%)$ were used frequently in the tweets circulated within WA. Table 10 lists the example tweets circulated related to the abovementioned words. These tweets showed economic challenges experienced by the local community such as unemployment and difficulty in paying mortgages.

The negatively classified tweets circulated within QLD, SA, and TAS included the words such as employment, spread, panic, confirm, business, risk, fear, anxious and cuts frequently.

\section{Linear}

Similar to the concave-up stage, $63 \%$ of total tweets circulated within this stage were negative. NSW, VIC, WA, and ACT had more tweets with negative sentiments.

The words such as lives (0.97\%), national (0.53\%), contract $(0.48 \%)$, offices $(0.44 \%)$, stop $(0.43 \%)$, positive $(0.44 \%)$, prevent $(0.42 \%)$ and employer $(0.4 \%)$ were popular among the tweets circulated in NSW in this phase. Tweets circulated within VIC carried more words such as arrival $(1.18 \%)$, immediate $(0.89 \%)$, employment $(0.73 \%)$, die $(0.6 \%)$, check $(0.56 \%)$, positive $(0.5 \%)$, cases $(0.45 \%)$, and days $(0.44 \%)$. The words such as suffer $(1.2 \%)$, arrival $(1 \%)$, hard $(0.71 \%)$, work $(0.66 \%)$, and dead $(0.47 \%)$ were frequently used in the tweets circulated within WA. Tweets collected from ACT had more words such as work $(0.96 \%)$, causes $(0.84 \%)$, cases $(0.57 \%)$, government $(0.42 \%)$, and spread $(0.41 \%)$. Example tweets related to the abovementioned words are given in Table 11.

Although QLD, SA, TAS and NT did not have more negatively classified tweets related to this stage, the words such as employment, death, issue, work, cuts, and businesses were popular among the negatively classified tweets.

\section{Concave-down}

Australia did not experience high infection cases and resulting deaths compared to other countries such as USA, Brazil, UK, and Italy. Within a shorter time period

Table 10 Example tweets with negative sentiments circulated within concave-up stage

\begin{tabular}{|c|c|c|c|}
\hline Date and time & State & Keyword & Exemplar tweets \\
\hline 06/03/2020 14:28 & WA & Die & 15 MILL people will die best-case coronavirus scenario \\
\hline $15 / 03 / 202004: 12$ & $\mathrm{VIC}$ & Arrival & $\begin{array}{l}\text { Advice on how self-isolate on arrival Australia please see their Dept of Health's guide COVID which covers this. } \\
\text { Don't create take risk }\end{array}$ \\
\hline 03/03/2020 08:20 & NSW & Work & $\begin{array}{l}\text { Can't stop COVID19 without protecting our health workers he said prices surgical masks increased sixfold while } \\
\text { cost ventilators had tripled he added }\end{array}$ \\
\hline 17/03/2020 21:06 & $\mathrm{ACT}$ & Mortgage & Wouldn't nice Aussie government absorb rent mortgages during hard times COVID-au \\
\hline 4/03/2020 07:46 & NSW & Cause & Who think coronavirus would cause toilet paper apocalypse \\
\hline
\end{tabular}


Table 11 Example tweets with negative sentiments circulated within linear stage

\begin{tabular}{|c|c|c|c|}
\hline Date and time & State & Keyword & Exemplar tweet \\
\hline 27/03/2020 02:33 & NSW & Arrival & Face masked ship crew arrive Sydney amid coronavirus warnings \\
\hline 19/03/2020 09:53 & VIC & Employment & $\begin{array}{l}\text { Really You don't think shutting down schools and keeping kids home won't make them stressed How about } \\
\text { when there's mass unemployment and Great Depression kids be stressed then There's longer game here } \\
\text { then just virus }\end{array}$ \\
\hline 20/03/2020 07:25 & WA & Suffer & $\begin{array}{l}\text { Watching Simpsons ep Bart tricks everyone cruise ship the world suffering virus they stay quarantined How } \\
\text { often they predict future }\end{array}$ \\
\hline 18/03/2020 08:25 & $\mathrm{ACT}$ & Work & People own business works themselves markets shows losing job no help coronavirus \\
\hline 11/03/2020 07:03 & NSW & Lives & $\begin{array}{l}\text { Scott Morrison MP Greg Hunt MP please before become China/Italy stop mass gatherings lock down few } \\
\text { weeks could make huge difference how many Aussies become ill coronavirusaustralia you will be saving } \\
\text { lives pandemic }\end{array}$ \\
\hline
\end{tabular}

Australia was able to control the pandemic situation. Soon after, the gap between negatively and positively classified tweets was narrowed down. However, still, $62 \%$ of the total tweets circulated within this phase were negative. NSW, VIC, ACT and WA had more negative tweets than positive ones. The tweets generated from the aforementioned states and territories in this stage either showed the reflections of the community about the life they experienced during the past days or the issues and problems they have to face in the upcoming new normal era.

Most of the tweets from NSW were generated around the words of employment $(0.84 \%)$, dead $(0.55 \%)$, cases $(0.53 \%)$, contract $(0.53 \%)$, days $(0.51 \%)$, novel $(0.48 \%)$, direction $(0.46 \%)$, experience $(0.46 \%)$, and cautious $(0.4 \%)$. Tweets from VIC had more words related to suffer $(1.28 \%)$, die $(0.66 \%)$, positive $(0.53 \%)$, cases $(0.53 \%)$, care $(0.5 \%)$ and days $(0.47 \%)$. Tweets from ACT mostly carried the words such as days $(0.62 \%)$, check $(0.54 \%)$, die $(0.5 \%)$, and cases $(0.4 \%)$. The words such as employment $(0.7 \%)$, days $(0.59 \%)$, check $(0.57 \%)$, people $(0.55 \%)$, backward $(0.53 \%)$, cases $(0.48 \%)$, hard $(0.47 \%)$, and miss $(0.45 \%)$ were the most popular in WA. Sample tweets circulated related to the frequently used words are given in Table 12.

Compared to other states and territories, the numbers of negatively classified tweets were slightly low in QLD,
SA, TAS. Nevertheless, the words such as employment, business, people, cases, spread, suffer, and industry were popular among the negatively classified tweets in QLD, SA, TAS and NT.

\section{Discussion}

The use of general public knowledge for public health policy and decision-making is becoming an important part of good governance practice [55-58]. Community juries [59], stakeholder meetings, community-based organisations [60], and non-government organisation feedbacks were often used by governments to aid the decision-making process [61]. Nonetheless, these cannot be used in pandemic situations, where social distancing is a compulsory rule. With the challenges of social distancing and travel restrictions, appropriate and community centric decisions need to be taken at the right time to tackle a pandemic situation successfully.

In the digital age, the use of social media data can help governments to capture community perceptions within a shorter time period without reaching the people directly/ physically [30]. This attribute of social media analytics make it qualified to be used to make community friendly decisions during pandemic situations. For instance, the findings of this study can assist policy- and decisionmakers in two ways: (a) To review community perceptions about the pandemic situation, and; (b) To identify

Table 12 Example of tweets with negative sentiments circulated within concave-down stage

\begin{tabular}{|c|c|c|c|}
\hline Date and time & State & Keyword & Exemplar tweets \\
\hline 22/03/2020 23:54 & WA & Employment & $\begin{array}{l}\text { Surely you can better your employees Armguard COVID19 NO masks NO gloves NO antibacterial wipes ATMs } \\
\text { would hive spreading germs well notes misinformation too responsibility the project }\end{array}$ \\
\hline 24/04/2020 06:45 & $\mathrm{VIC}$ & Suffer & $\begin{array}{l}\text { Proud Daniel Andrews MP not giving populist attitude demands sticking restrictions coronavirus crisis } \\
\text { Another week doesn't hurt anyone even though suffer financially etc }\end{array}$ \\
\hline 27/03/2020 04:33 & $\mathrm{ACT}$ & Days & Australia records highest single day increase coronavirus cases \\
\hline 03/04/2020 20:35 & NSW & Employment & Impact vast International student's university school employment Coronavirus COVID-AU \\
\hline 18/04/2020 02:23 & NSW & Dead & $\begin{array}{l}\text { Nearly lost Two people laughed me told couldn't use fitting rooms virus exactly funny deadly virus killing } \\
\text { people over world }\end{array}$ \\
\hline
\end{tabular}


the key requirements of the community to cope up with the pandemic situation.

The analysis has shown that Australian public was not happy at the early stage of the pandemic curve-i.e., preconcave stage-as they seemed to believe that the Australian government was not responding to this global disaster appropriately. Accordingly, people were in a panic mode, and tried to prepare to face the pandemic at their capacity. The words, toilet/paper were very common in Twitter in all states/territories during the preconcave stage. This was because consumer panic buying patterns took place in Australia, where people tried to stock toilet papers, hand sanitisers, food and other commodities. This indicated how Australian people act when the government does not provide confidence.

From February 2020 onwards, the Australian government started to add travel restrictions to combat COVID-19. This made people started to build trust in the government. The popular words among positively classified tweets showed that the people were generally happy about the actions taken by the government to combat the virus dispersion in Australia. Frequently used words, such as testing, resources, shutdown, and reaction, showed the awareness level of the community to face an upcoming disaster. For instance, the tweets circulated in QLD emphasised the significance of expending the number of testing per day at the early stage to stop spreading the virus rapidly. Furthermore, most of the tweets discussed about the importance of wearing masks.

Especially, people looked satisfied about the decisions made to expand the testing to reduce spreading SARS$\mathrm{CoV}-2$. For instance, the Australian government conducted more than two million tests in Australia by the end of May 2020. The majority of these tests were conducted in the following states: NSW $(\mathrm{n}=725,817)$, VIC $(\mathrm{n}=660,801)$, QLD $(\mathrm{n}=274,688)$, and SA $(\mathrm{n}=137,290)$ [62]. The action of expanding the testing was taken during the late March 2020. Yet, it was also well demanded in the tweets circulated during the beginning of March 2020.

Most of the tweets reflected positive sentiments about the policy decisions to limit travelling such as closing state borders to non-citizens and residents, blocking Iran, South Korea and Italy arrivals, contract tracing and limiting outdoor and indoor gatherings. Furthermore, the Australian government introduced two mobile applications: (a) Coronavirus Australia App, and; (b) COVIDSafe App. They were ranked over four out of five points in both Apple and Android app stores. While such apps are immensely useful, effective use of government social media channels are also required to help the public follow the introduced measures/restrictions. Previous studies have shown the limitations of the government agencies in effective use of social media channels in Australia [63].

These applications provided timely demanded information package to the people such as the reported cases by state, advices, symptom checker, location information related to general practitioner respiratory clinics, register to self-isolate, mental health advices, special advices to the age care sector, health information contact number and so on. The COVIDSafe app is designed to help the Australian government to find close contacts of COVID-19 infected people. This app allows state and territory health officials to quickly contact people that may have been infected with the virus. Factually, people looked satisfied and happy about the decisions took by the Australian government to slow down the spread of the virus. While people were sending tweets related to the policies taken, there were more words related to the economy in the negatively classified tweets. The tweets shared related to financial issues got three forms: (a) Panic buying-related issues; (b) Mortgage-related issues, and; (c) Employmentrelated issues.

The very first economy-related issue faced by Australians was the stock outrage due to the consumer 'panic buying. As a result, the supply of toilet papers and other commodities were significantly low in NSW, VIC and WA. This situation made supermarkets to limit the number of items per transaction/per customer. Some supermarkets announced plans to give priority to elderly and disabled people when selling their goods. As COVID-19 started to hit Australia after the bushfire, the situation become dire with the consumer panic buying patterns. Moreover, the discussions about the positive relationship between elderly population and the fatality rates increased the death fear of Australians from COVID-19 [64].

The words such as businesses, employments, salary cuts, investments, and industries were the first plural cluster of words among the tweets with negative sentiments. Especially, these words were very popular among the tweets generated from NSW, VIC, and ACT. It was estimated that around one million Australians lost their jobs due to the pandemic. This was more significant in VIC, TAS and SA [65]. Although SA had more positive perceptions, the word of employment $(1.54 \%)$ was common among the negatively classified tweets. These facts showed the financial stress of the community during the pandemic, to which government needs to respond immediately.

The second issue was related to the 'mortgage' payments, which was the second popular word cluster within the negatively classified tweets. The COVID-19 pandemic left 1.4 million Australian in mortgage stress 
[66]. According to Australian Bureau of Statistics (2018), NSW $(\$ 462,100)$, VIC $(\$ 400,400)$, and ACT $(\$ 404,200)$ owned the highest average mortgage sizes among the other states/territories. Thus, people from these states/ territories undergo severe financial issues at a time, when they may not be engaging in paid work/employment.

The third issue was related to 'employment'. While the Australian government's JobSeeker and JobKeeper programs are helpful to a degree [67], the uncertainty of these programs generates an anxiety among the people who either lost or might be losing their jobs. It highlights the fact that after controlling the pandemic in a successful way the next challenge waiting for the Australian government is to stimulate the downturn economy of Australia - that is already in recession-due to the COVID-19 pandemic. Along with this, the postCOVID-19 era might subject to a prolonged state of psychological fear, worries, and confusion against any small to large scale physical gathering [68]. A timely and sound government response, hence, is needed.

\section{Conclusion}

The unpredictable, sudden and rapid emergence and transmission of COVID-19, during the last few months, has triggered significant public health emergencies and concern across both national as well as the global nature. Considering limited availability of clinically proven interventions and the infectious nature of the SARS-CoV-2's transmission, there created a global emergency in the form of a pandemic, resulting in implementations of lockdowns and restrictions in movement for citizens throughout the world. The resultant limitations have, thus, sparked a surge in the usage of online resources by the public, such as the usage of social media as well as the public's reliance on e-commerce services for the purpose of obtaining essential commodities.

Considering the increasing influence of social media across the public, especially during the time of restricted movement like the existing lockdown, this paper examined the potential role of crowdsourced data drawn from social media in informing the government policy-and decision-making process during a pandemic. The dearth of existing evidence, implemented specifically in the Australian context, further prompted the execution of this research. Accordingly, for the purpose of expounding upon the role of social media analytics in influencing governmental policy-and decision-making during a pandemic, a social media analysis approach was adopted by this research, comprising of a systematic and geographical analysis of 35,969 geotagged tweets of individuals residing in Australian states/territories.

The findings revealed the prevalence of negatively classified tweets (63\%), compared with positively classified ones (37\%). The highest prevalence of negatively classified tweets was reported during the pre-concave stage, while the lowest prevalence of $62 \%$ was observed during the concave-down stage. The highest prevalence of negatively classified tweets was observed from such territories and states as NSW, VIC, WA, and ACT, where additional 9885 negative tweets, reflecting the prevalence of concerns regarding a pandemic from the public during stages before transmission of the virus.

Indeed, the concave-up stage or the period of rapid disease transmission was characterised as a relatively short period in Australia, along with the implementation of 21 major governmental responses (14 health and 7 economic responses) to mitigate the impacts of COVID-19. Such data on governmental actions can be well correlated with the reporting of the smallest number of negative tweets during this period by the public. Additionally, the findings also demonstrated the prevalent financial issues faced by the public during the pandemic. Issues related to financial crisis were observed in the negative tweets where the public primarily shared concerns related to: (a) Bulk purchasing due to panic; (b) Inability or difficulty to pay mortgages, and; (c) Loss or risk of employment. Such findings, thus, depicted the financial issues faced by the public during national emergency situations like a pandemic, which the government must act upon immediately along with disease prevention.

The overall study findings reveal that: (a) Social media analytics is an efficient approach to capture the attitudes and perceptions of the public during a pandemic; (b) Crowdsourced social media data can guide interventions and decisions of the authorities during a pandemic, and; (c) Effective use of government social media channels can help the public to follow the introduced measures/ restrictions.

These findings, thus, demonstrate the effectiveness of social media analytics in depicting the public's expectations in response to a national emergency or crisis situation, especially when the governments cannot reach the general public directly/physically. The findings of this research, thus, proved to be useful in recommending and evaluating the potential effectiveness of crowdsourced data from the public's social media activities in informing governmental authorities on possible strategies to implement during a pandemic. To conclude, the findings of this research, hence, recommend governmental authorities to: (a) Conduct social media analytics to capture public perceptions and act accordingly, and; (b) Actively utilise social media channels to enhance public health education and awareness concerning social distancing restrictions to be maintained during COVID-19 or other future pandemics. 
Lastly, the following limitations of the study should be considered when interpreting the findings. First, the study only covered the period between 1 January and 4 May 2020, when the COVID-19 pandemic still prevailed in Australia at different degrees after this period. Second, as the case of VIC indicated, the four stages of pandemic may repeat again with the identification of newly infected clusters-this was the case for Melbourne on the first week of July 2020 (i.e., Victorian government's lockdown of nine public housing towers in Melbourne, and the lockdown was expanded to the Melbourne metropolitan area in the next days). Third, this study only analysed Twitter data, while other social media channels were not considered. Finally, there might be bias involved in the selection of the word bags and also when supervising the machine learning tool in the used software-i.e., WEKA.

\section{Acknowledgements}

The authors cordially thank the Editor-in-Chief Prof. Yanchun Zhang, Managing Editor Prof. Siuly Siuly, and two anonymous referees for their invaluable comments on an earlier version of the manuscript. The authors also acknowledge the assistance provided by QUT Digital Observatory's data scientist Sam Hames in obtaining the social media data used in the study.

\section{Author contributions}

The first author designed and lead the study, set up the research team, and finalised the manuscript. The second author managed the data collection, cleaning and analysis stages, supervised the third to sixth authors' work, and contributed to the write-up. The third to sixth authors helped in the data cleaning and analysis stages, and contributed to the write-up. The seventh and eighth authors edited the manuscript, and improved the rigor, relevance and reach of the study.

\section{Funding}

This research did not receive any specific grant from funding agencies in the public, commercial or not-for-profit sectors.

\section{Compliance with ethical standards}

\section{Conflict of interest}

The authors declare that they have no known competing financial interests or personal relationships (or any other conflict of interest) that could have appeared to influence the work reported in this paper.

\section{Ethical approval}

Ethical approval was obtained from Queensland University of Technology's Human Research Ethics Committee (\#1900000214).

\section{Author details}

${ }^{1}$ School of Built Environment, Queensland University of Technology, 2 George Street, Brisbane, QLD 4000, Australia. ${ }^{2}$ Department of Architecture, Nangarhar University, Kabul-Jalal Abad Highway, Jalalabad, Nangarhar 2601, Afghanistan. ${ }^{3}$ Department of Urban Planning, Islamic Azad University, Shariati Street, 19395 Tehran, Iran. ${ }^{4}$ Department of Economics, University of Messina, Piazza Pugliatti, 1, 98122 Messina, Italy.

Received: 10 July 2020 Accepted: 14 September 2020

Published online: 15 October 2020

\section{References}

1. Qiu W, Rutherford S, Mao A, Chu C. The pandemic and its impacts. Health Cult Soc. 2017:9:1-11.
2. Reshadat S, Zangeneh A, Saeidi S, Teimouri R, Yigitcanlar T. Measures of spatial accessibility to health centers: investigating urban and rural disparities in Kermanshah. Iran J Public Health. 2019;27(1):519-29.

3. Saunders-Hastings PR, Krewski D. Reviewing the history of pandemic influenza: understanding patterns of emergence and transmission. Pathogens. 2016;5(4):66

4. Tumpey TM, Basler CF, Aguilar PV, Zeng H, Solórzano A, Swayne DE, Garcia-Sastre A. Characterization of the reconstructed 1918 Spanish influenza pandemic virus. Science. 2005;310(5745):77-80.

5. WHO. Strengthening and adjusting public health measures throughout the COVID-19 transition phases: policy considerations for the World Health Organization European Region. Copenhagen: World Health Organization. Regional Office for Europe; 2020.

6. Worldometer. COVID-19 Coronavirus pandemic.https://www.worldomete rs.info/coronavirus (2020). Accessed 1 July 2020.

7. Zhang Y, Xiao M, Zhang S, Xia P, Cao W, Jiang W, Wang C. Coagulopathy and antiphospholipid antibodies in patients with Covid-19. N Engl J Med. 2020;382(17):e38

8. Ling GH, Chyong Ho CM. Effects of the coronavirus (COVID-19) pandemic on social behaviors: from a social dilemma perspective. Tech Soc Sci J. 2020;7:312-20

9. Daneshpour ZA: Out of the coronavirus crisis, a new kind of urban planning must be born. https://novinshahrsaz.ir/wp-content/uploa ds/2020/04/Out_of_the_coronavirus_crisis_a_new_kind_of_urban _planning_must.pdf (2020). Accessed 30 June 2020.

10. Honey-Roses JH, Anguelovski I, Bohigas J, Chireh V, Daher C, Konijnendijk C, Litt J, Mawani J, McCall M, Orellana A, Oscilowicz E, Sanchez U, Senbe M, Tan X, Villagomez E, Zapata O, Nieuwenhuijsen M: The Impact of COVID-19 on Public Space: a Review of the Emerging Questions. https:// doi.org/10.31219/osf.io/rf7xa (2020). Accessed 25 June 2020.

11. Newman P. Covid, cities and climate: historical precedents and potential transitions for the new economy. Urban Sci. 2020;4(3):32.

12. Statista: Mobility in cities amid coronavirus crisis 2020. https://www.stati sta.com/statistics/1106798/change-in-traffic-volume-amid-coronaviru scrisis-selected-cities (2020). Accessed 25 June 2020.

13. Jones CJ, Philippon T, Venkateswaran V. Optimal mitigation policies in a pandemic: social distancing and working from home. https://www.nber. org/papers/w26984 (2020). Accessed 1 July 2020.

14. Shenker J. Cities after coronavirus: how COVID-19 could radically alter urban life. https://www.theguardian.com/world/2020/mar/26/life-after -coronavirus-pandemic-change-world (2020). Accessed 25 June 2020.

15. Alzahrani $\mathrm{H}$. Social media analytics using data mining. Glob J Comput Sci Technol. 2016;16(4):16-9.

16. Brooker P, Barnett J, Cribbin T. Doing social media analytics. Big Data Soc. 2016;3(2):2053951716658060.

17. Sebei H, Taieb MA, Aouicha MB. Review of social media analytics process and big data pipeline. Soc Netw Anal Min. 2018;8(1):30.

18. Reshadat S, Tohidi M, Ghasemi M, Zangeneh A, Saeidi S, Teimouri R, Yigitcanlar T. Interrelationship between underprivileged neighborhoods and health promotion lifestyles: insights from Kermanshah, Iran. J Public Health. 2019. https://doi.org/10.1007/s10389-019-01086-0.

19. Chowell G, Viboud C, Hyman JM, Simonsen L. The Western Africa ebola virus disease epidemic exhibits both global exponential and local polynomial growth rates. PLoS Curr. 2015;7:3261.

20. Fraser C, Riley S, Anderson RM, Ferguson NM. Factors that make an infectious disease outbreak controllable. Proc Natl Acad Sci. 2004;101(16):6146-51.

21. Rochester Regional Health. Pandemic vs Epidemic: what's the difference? https://www.rochesterregional.org/news/2020/03/pandemic-vs-epide mic (2020). Accessed 25 June 2020.

22. Bharat D. COVID-19: the four stages of disease transmission explained. https://www.netmeds.com/health-library/post/covid-19-the-4-stages-ofdisease-transmission-explained (2020). Accessed 25 June 2020.

23. Wade A. COVID -19 coronavirus alert level 2: NZ lockdown debate, more help for firms as global deaths soar past 13,500. https://www.nzherald. co.nz/nz/news/article.cfm?c_id=1\&objectid=12318890 (2020). Accessed 2 July 2020

24. Gavin K. Flattening the curve for COVID-19: what does it mean and how can you help? https://healthblog.uofmhealth.org/wellness-prevention/ flattening-curve-for-covid-19-what-does-it-mean-and-how-can-you-help (2020). Accessed 25 June 2020. 
25. Hu R. Reinventing community in COVID-19: a case in Canberra, Australia. Soc-Ecol Pract Res. 2020. https://doi.org/10.1007/s42532-020-00055-2.

26. Department of Health. Easing of coronavirus (COVID-19) restrictions. https://www.health.gov.au/news/health-alerts/novel-coronavirus-2019ncov-health-alert/coronavirus-covid-19-restrictions/easing-of-coronaviru s-covid-19-restrictions (2020). Accessed 25 June 2020.

27. Wargent P. Miraculous improvement in COVID-19 cases. https://www. propertyobserver.com.au/pete-wargent/112767-miraculous-impro vement-in-covid-19-cases-pete-wargent.html (2020). Accessed 25 June 2020.

28. Pueyo T. Coronavirus: the hammer and the dance. https://mediu m.com/@tomaspueyo/coronavirus-the-hammer-and-the-dance-be933 7092 b56 (2020). Accessed 25 June 2020.

29. Kankanamge N, Yigitcanlar T, Goonetilleke A, Kamruzzaman M. Can volunteer crowdsourcing reduce disaster risk? A systematic review of the literature. Int J Disaster Risk Reduct. 2019;35:101097.

30. Kankanamge N, Yigitcanlar T, Goonetilleke A, Kamruzzaman M. How can gamification be incorporated into disaster emergency planning? A systematic review of the literature. Int J Disaster Resil Built Environ. 2020a; 11(4):481-506

31. Paul MJ, Dredze M. Discovering health topics in social media using topic models. PLoS ONE. 2014;9(8):e103408.

32. Eichstaedt JC, Schwartz HA, Kern ML, Park G, Labarthe DR, Merchant RM, Weeg C. Psychological language on Twitter predicts county-level heart disease mortality. Psychol Sci. 2015;26(2):159-69.

33. Signorini A, Segre AM, Polgreen PM. The use of Twitter to track levels of disease activity and public concern in the US during the influenza A H1N1 pandemic. PLoS ONE. 2011;6(5):e19467.

34. Harris JK, Mueller NL, Snider D. Social media adoption in local health departments nationwide. Am J Public Health. 2013;103(9):1700-7.

35. Scanfeld D, Scanfeld V, Larson EL. Dissemination of health information through social networks: Twitter and antibiotics. Am J Infect Control. 2010;38(3):182-8.

36. Moreno MA, Arseniev-Koehler A, Litt D, Christakis D. Evaluating college students' displayed alcohol references on Facebook and Twitter. J Adolesc Health. 2016;58(5):527-32.

37. Jones R, Kelsey J, Nelmes P, Chinn N, Chinn T, Proctor-Childs T. Introducing Twitter as an assessed component of the undergraduate nursing curriculum: case study. J Adv Nurs. 2016;72(7):1638-53.

38. Devi S. Twitter campaign highlights top women in global health. Lancet. 2015;385(9965):318

39. Cowling D. SocialMediaNews.com.au. Social Media Statistics AustraliaJanuary 2020. https://www.socialmedianews.com.au/social-media-stati stics-australia-january-2020 (2020). Accessed 25 June 2020.

40. Sensis. Yellow Social Media Report 2018. Part one: consumers. https:// www.yellow.com.au/wp-content/uploads/2018/06/Yellow-Social-Media -Report-2018-Consumer.pdf (2018). Accessed 25 June 2020.

41. Australian Government. Coronavirus (COVID-19) current situation and case numbers. https://www.health.gov.au/news/health-alerts/nove -coronavirus-2019-ncov-health-alert/coronavirus-covid-19-current-situa tion-and-case-numbers (2020). Accessed 25 June 2020

42. NSW Government. The Special Commission of Inquiry into the Ruby Princess. https://www.rubyprincessinquiry.nsw.gov.au (2020). Accessed 25 June 2020

43. Faasse K, Newby JM. Public perceptions of COVID-19 in Australia: perceived risk, knowledge, health-protective behaviours, and vaccine intentions. medRxiv. 2020. https://doi.org/10.1101/2020.04.25.20079996.

44. Yigitcanlar T, Kankanamge N, Vella K. How are the smart city concepts and technologies perceived and utilized? A systematic geo-twitter analysis of smart cities in Australia. J Urban Technol. 2020. https://doi. org/10.1080/10630732.2020.1753483.

45. Arthur R, Boulton CA, Shotton H, Williams HT. Social sensing of floods in the UK. PLOS ONE. 2018;13(1):e0189327.

46. Kankanamge N, Yigitcanlar T, Goonetilleke A, Kamruzzaman M. Determining disaster severity through social media analysis: testing the methodology with South East Queensland Flood Tweets. Int J Disaster Risk Reduct. 2020b;42(1):101360.
47. Anderson RM, Heesterbeek H, Klinkenberg D, Hollingsworth TD. How will country-based mitigation measures influence the course of the COVID19 epidemic? Lancet. 2020;395(10228):931-4.

48. Department of Health. Coronavirus (COVID-19) at a glance - 5 May 2020, Department of Health, Australian Government. https://www.health.gov. au/resources/publications/coronavirus-covid-19-at-a-glance-5-may-2020 (2020). Accessed 28 June 2020.

49. Australian Government. Economic response to the coronavirus. https:// treasury.gov.au/sites/default/files/2020-05/Overview-Economic_Respo nse_to_the_Coronavirus_3.pdf. (2020). Accessed 23 June 2020.

50. Australian Bureau of Statistics. Housing finance, Australia, November 2018. https://www.abs.gov.au/ausstats/abs@.nsf/e8ae5488b598839cca25 682000131612/d672cf4ebe195f15ca256e910077d9c2!OpenDocument (2018). Accessed 3 July 2020.

51. Castillo C, Mendoza M, Poblete B. Predicting information credibility in time-sensitive social media. Internet Res. 2013;23(5):560-88.

52. Feng $Y$, Sester M. Extraction of pluvial flood relevant volunteered geographic information (VGI) by deep learning from user generated texts and photos. ISPRS Int J Geo-Inf. 2018;7(2):39.

53. Kankanamge N, Yigitcanlar T, Goonetilleke A. How engaging are disaster management related social media channels? The case of Australian state emergency organisations. Int J Disaster Risk Reduct. 2020;48(1):101571.

54. Department of Health. Coronavirus (COVID-19) current situation and case numbers, Department of Health, Australian Government. https://www. health.gov.au/news/health-alerts/novel-coronavirus-2019-ncov-healt h-alert/coronavirus-covid-19-current-situation-and-case-numbers\#tests -conducted-and-results (2020). Accessed 28 June 2020.

55. Baum S, Kendall E, Muenchberger H, Gudes O, Yigitcanlar T. Geographical information systems: an effective planning and decision-making platform for community health coalitions in Australia? Health Inf Manag J. 2010;39(3):28-33.

56. Gudes O, Kendall E, YigitcanlarT, Pathak V, Baum S. Rethinking health planning: a framework for organising information to underpin collaborative health planning. Health Inf Manag J. 2010;39(2):18-29.

57. Vaeztavakoli A, Lak A, Yigitcanlar T. Blue and green spaces as therapeutic landscapes: health effects of urban water canal areas of Isfahan. Sustainability. 2018;10(11):4010.

58. Yigitcanlar T, Kamruzzaman M, Teimouri R, Degirmenci K, Aghnayi F. Association between park visits and mental health in a developing county context: the case of Tabriz, Iran. Landsc Urban Plan. 2020;199(1):103805.

59. Degeling C, Rychetnik L, Street J, Thomas R, Carter SM. Influencing health policy through public deliberation: lessons learned from two decades of Citizens'/community juries. Soc Sci Med. 2017;179:166-71.

60. Israel BA, Coombe CM, Cheezum RR, Schulz AJ, McGranaghan RJ, Lichtenstein R, Burris A. Community-based participatory research: a capacitybuilding approach for policy advocacy aimed at eliminating health disparities. Am J Public Health. 2010;100(11):2094-102.

61. Smith BL. The non-governmental policy analysis organization. Public Adm Rev. 1977:37:253-8.

62. Department of Health. First confirmed case of novel coronavirus in Australia, Department of Health, Australian Government. https://www.healt h.gov.au/ministers/the-hon-greg-hunt-mp/media/first-confirmed-caseof-novel-coronavirus-in-australia (2020). Accessed 22 June 2020.

63. Yigitcanlar T, Goonetilleke A, Kankanamge N. Disasters expose gaps in emergency services' social media use. https://theconversation.com/disas ters-expose-gaps-in-emergency-services-socialmedia-use-134912 (2020). Accessed 5 July 2020.

64. Holt NR, Neumann JT, McNeil JJ, Cheng AC, Unit HE, Prahan V. Implications of COVID-19 in an ageing population. Med J Aust. https://www.mja. com.au/system/files/2020-05/Holt\%20mja20.00649\%20-\%206\%20May \%202020.pdf (2020). Accessed 30 June 2020

65. ABC. Almost a million Australians out of work due to coronavirus; RBA tips economy to take 10pc hit. ABC News. https://www.abc.net.au/ news/2020-05-05/almost-one-million-australians-lose-jobs-due-to-coron avirus/12215494 (2020a). Accessed 25 June 2020.

66. Cassells R, Duncan A. JobKeepers and JobSeekers: how many workers will lose and how many will gain? https://bcec.edu.au/assets/2020/03/ 
BCEC-COVID19-Brief-3-Job-Seekers-and-Keepers_FINAL.pdf (2020). Accessed 1 July 2020

67. ABC. Coronavirus recession leaves $1.4 \mathrm{~m}$ Australians in mortgage stress, almost 100,000 could default after JobKeeper ends. ABC News. https ://www.abc.net.au/news/2020-06-04/covid-recession-mortgage-stres s-default-home-loans-jobkeeper/12318274 (2020). Accessed 25 June 2020.

68. Ho CS, Chee CY, Ho RC. Mental health strategies to combat the psychological impact of COVID-19 beyond paranoia and panic. Ann Acad Med Singap. 2020;49(1):1-3. 